\title{
Structural Similarities between Neuregulin 1-3 Isoforms Determine Their Subcellular Distribution and Signaling Mode in Central Neurons
}

\author{
Detlef Vullhorst, ${ }^{\star}$ Tanveer Ahmad, ${ }^{*}$ Irina Karavanova, Carolyn Keating, and Andres Buonanno \\ Section on Molecular Neurobiology, Eunice Kennedy Shriver National Institute of Child Health and Human Development, Bethesda, Maryland 20892
}

The Neuregulin (NRG) family of ErbB ligands is comprised of numerous variants originating from the use of different genes, alternative promoters, and splice variants. NRGs have generally been thought to be transported to axons and presynaptic terminals where they signal via ErbB3/4 receptors in paracrine or juxtacrine mode. However, we recently demonstrated that unprocessed pro-NRG2 accumulates on cell bodies and proximal dendrites, and that NMDAR activity is required for shedding of its ectodomain by metalloproteinases. Here we systematically investigated the subcellular distribution and processing of major NRG isoforms in rat hippocampal neurons. We show that NRG1 isotypes I and II, which like NRG2 are single-pass transmembrane proteins with an Ig-like domain, share the same subcellular distribution and ectodomain shedding properties. We furthermore show that NRG3, like CRD-NRG1, is a dual-pass transmembrane protein that harbors a second transmembrane domain near its amino terminus. Both NRG3 and CRD-NRG1 cluster on axons through juxtacrine interactions with ErbB4 present on GABAergic interneurons. Interestingly, although single-pass NRGs accumulate as unprocessed proforms, axonal puncta of CRD-NRG1 and NRG3 are comprised of processed protein. Mutations of CRD-NRG1 and NRG3 that render them resistant to BACE cleavage, as well as BACE inhibition, result in the loss of axonal puncta and in the accumulation of unprocessed proforms in neuronal soma. Together, these results define two groups of NRGs with distinct membrane topologies and fundamentally different targeting and processing properties in central neurons. The implications of this functional diversity for the regulation of neuronal processes by the NRG/ErbB pathway are discussed.

Key words: BACE; ErbB4; metalloproteinases; Neuregulin; NMDA receptor; processing

Significance Statement

Numerous Neuregulins (NRGs) are generated through the use of different genes, promoters, and alternative splicing, but the functional significance of this evolutionary conserved diversity remains poorly understood. Here we show that NRGs can be categorized by their membrane topologies. Single-pass NRGs, such as NRG1 Types I/II and NRG2, accumulate as unprocessed proforms on cell bodies, and their ectodomains are shed by metalloproteinases in response to NMDA receptor activation. By contrast, dual-pass CRD-NRG1 and NRG3 are constitutively processed by BACE and accumulate on axons where they interact with ErbB4 in juxtacrine mode. These findings reveal a previously unknown functional relationship between membrane topology, protein processing, and subcellular distribution, and suggest that single- and dual-pass NRGs regulate neuronal functions in fundamentally different ways.

\section{Introduction}

Neuregulins (NRGs) signal via ErbB3/4 receptor tyrosine kinases to regulate numerous neurodevelopmental and activity-dependent processes (Buonanno, 2010; Mei and Nave, 2014). For example, NRG/ErbB4 signaling in parvalbumin-positive GABAergic interneurons regulates glutamatergic synaptic plasticity in the hip-

\footnotetext{
Received Aug. 19, 2016; revised March 14, 2017; accepted April 9, 2017.

Author contributions: D.V., T.A., and A.B. designed research;D.V., T.A., I.K., and C.K. performed research;D.V. and T.A. contributed unpublished reagents/analytic tools; D.V., T.A., and A.B. analyzed data; D.V., T.A., and A.B. wrote the paper.

This work was supported by Eunice Kennedy Shriver Institute of Child Health and Human Development Intramural Research Program. We thank Drs. Vincent Schram and Carolyn Smith (Porter Neuroscience Center imaging core) for expert assistance with confocal microscopy; and Dr. Jung-Hwa Tao-Cheng (National Institute of Neurological Disorders and Stroke EM facility) for help with immunogold EM microscopy.
}

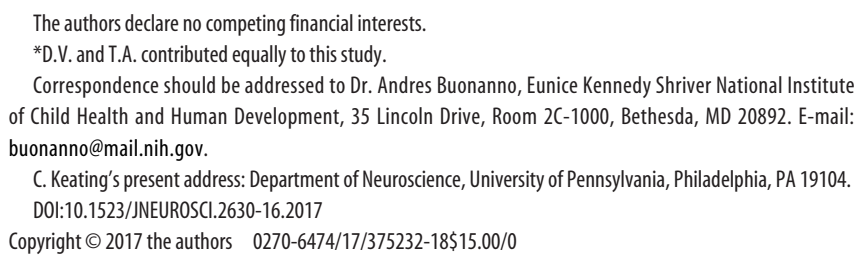
of Child Health and Human Development, 35 Lincoln Drive, Room 2C-1000, Bethesda, MD 20892. E-mail: buonanno@mail.nih.gov.

C. Keating's present address: Department of Neuroscience, University of Pennsylvania, Philadelphia, PA 19104. D0I:10.1523/JNEUROSCI.2630-16.2017

Copyright $\odot 2017$ the authors $\quad 0270-6474 / 17 / 375232-18 \$ 15.00 / 0$ 
pocampus (Chen et al., 2010; Shamir et al., 2012) and critical period plasticity in the visual cortex (Gu et al., 2016; Sun et al., 2016). NRGs are encoded by four genes, of which $n$ rg1-3 are expressed in the nervous system. All NRGs share an EGF-like domain that mediates receptor binding and initiation of downstream signaling. NRG1 isoform diversity results from the use of multiple promoters that give rise to unique amino-terminal sequences of NRG Types I-VI, and by alternative splicing of sequences encoding both the extracellular and intracellular domains (Falls, 2003; Steinthorsdottir et al., 2004). Proforms of canonical NRGs, such as NRG1 Types I/II and NRG2, harbor a single transmembrane pass $\left(\mathrm{TM}_{\mathrm{C}}\right)$ downstream of the EGF-like motif that separates the amino-terminal extracellular domain (ECD) from the carboxyl-terminal intracellular domain (ICD). They additionally contain an immunoglobulin-like (Ig) motif that mediates interactions with heparan sulfate proteoglycans in the extracellular matrix (Loeb and Fischbach, 1995). Ig-NRGs shed their ectodomains upon proteolytic processing near the $\mathrm{TM}_{\mathrm{C}}$, which then interact with ErbB receptors in paracrine manner. By contrast, NRG1 isoforms transcribed from the Type III promoter lack the Ig-like motif and instead contain a cysteinerich domain (CRD) near their amino terminus that serves as a second transmembrane domain $\left(\mathrm{TM}_{\mathrm{N}}\right)$. As a result, CRD-NRG1 remains cell-attached after cleavage and signals in juxtacrine fashion (Wang et al., 2001). NRG3, whose mode of signaling has not been reported, lacks both Ig-like and CRD motifs but includes a stretch of hydrophobic residues near its amino terminus (Zhang et al., 1997).

Historically, the relationship between domain organization, signaling mode, and biological function has been most extensively explored for CRD-NRG1. In particular, juxtacrine interactions between CRD-NRG1 on sensory neuron or motorneuron axons and ErbB2/3 receptors on glial cells are essential for Schwann cell development and functional maturation (Garratt et al., 2000; Nave and Salzer, 2006), and mice lacking this isoform exhibit deficient myelination of peripheral nerves resulting in neonatal lethality (Wolpowitz et al., 2000). Axonal accumulation of CRDNRG1 has therefore served as a general paradigm for subcellular NRG targeting. Less is known about the in vivo functions of single-pass Ig-NRG1s in neuronal development because mice lacking the Ig-like motif die at E10.5 due to deficient myocardial trabeculation (Kramer et al., 1996; Meyer et al., 1997), although an essential role for glial-derived Type 1 NRG1 has been demonstrated during Schwann cell regeneration following peripheral nerve denervation (Carroll et al., 1997; Hayworth et al., 2006; Stassart et al., 2013).

We recently reported that unprocessed NRG2, a major IgNRG in the adult rodent brain, clusters on the soma and proximal dendrites of NRG2-expressing cells, such as ErbB4-positive GABAergic interneurons and cerebellar Purkinje neurons, rather than accumulating on axons (Vullhorst et al., 2015). Pro-NRG2 targets to a distinct type of ER-PM contact site characterized by endoplasmic reticulum specializations known as subsurface cisterns (SSCs) (Berridge, 1998), and colocalizes with Kv2.1 potassium channels (Du et al., 1998; Misonou et al., 2004). Ectodomain shedding is mediated by metalloproteinases and requires NMDA receptor (NMDAR) activity (Vullhorst et al., 2015). Interestingly, NRG1 has recently been reported to accumulate postsynaptically at C-boutons, cholinergic synapses between local interneurons and $\alpha$-motorneuron cell bodies (GallartPalau et al., 2014), which form atop SSCs and contain Kv2.1 channel clusters (Deardorff et al., 2014). However, the type of NRG1 expressed at C-boutons is not known.
In this study, we delineated general principles underlying the relationship between domain structure, subcellular distribution, and ectodomain shedding of major NRG isoforms in central neurons, including NRG1 Types I/II, NRG2, and NRG3. Our data show that single-pass NRGs share the same subcellular targeting and NMDAR-dependent ectodomain shedding properties, whereas the dual-pass proteins CRD-NRG1 and NRG3 accumulate as processed proteins on axons through juxtracrine interactions with ErbB4. Furthermore, processing of single-pass NRGs is mediated by metalloproteinases, whereas dual-pass NRGs are processed by BACE. Together, these findings establish a rational basis to understand NRG isoform diversity and function in cell biological terms.

\section{Materials and Methods}

Animals. Sprague Dawley rats of either sex were used for tissue culture and RNA analysis. Wild-type C57BL/6J mice of either sex were used for immunohistochemistry and ISH. Animals were treated in accordance with National Institutes of Health Animal Welfare guidelines. All procedures were approved by the National Institute of Child Health and Human Development Animal Care and User Committee.

Antibodies. Antibodies included the following: rabbit monoclonal mAB11 against NRG2 (Vullhorst et al., 2015); mouse monoclonal against Ankyrin G (clone N106/65; NeuroMab); rabbit polyclonal custom antibody 5721 against Erbb4 (for immunization strategy, see Vullhorst et al., 2009); mouse monoclonal against Kv2.1 (clone K89/34; NeuroMab); rabbit polyclonal against NRG1 (SC-348; Santa Cruz Biotechnology); mouse monoclonal against V5 tag (clone SV-Pk1; BioRad); mouse monoclonal against HA tag (clone 16B12; Abcam); mouse monoclonal against PSD95 (clone 7E3-1B8; Thermo Fisher); rat monoclonal against GFP (clone GF090R; Nacalai Tesque); guinea pig polyclonal against parvalbumin (Synaptic Systems); and guinea pig polyclonal against vesicular acetylcholine transporter (vAChT; Synaptic Systems).

Generation of an attenuated CMV promoter to drive low-level NRG expression in transfected hippocampal neurons. To attain low to moderate NRG expression levels in transfected cultured neurons, the $586 \mathrm{bp}$ wildtype CMV promoter was "gutted" to lower its transcriptional output, following a previously described strategy (Watanabe and Mitchison, 2002). Briefly, a 434 bp internal fragment was removed from the promoter by sequential treatment with the endonuclease AatII and the exonuclease Bal-31. Residual promoter strength was assessed by transient transfection of HEK 293 cells and 10 days in vitro (DIV) cultured hippocampal neurons with vector pGL3basic (Promega) harboring the attenuated CMV promoter. Relative luciferase activity, measured $1 \mathrm{~d}$ after transfection and normalized by cotransfection with pRL Renilla (Promega), was $14.1 \pm 1.6 \%$ of wild-type CMV in HEK 293 cells $(n=3$ independent experiment, each run in triplicate) and $38.9 \pm 1.2 \%$ in hippocampal neurons ( $n=4$ independent experiments, each run in duplicate). To generate the corresponding attenuated NRG expression vectors, the luciferase sequence was first replaced by a Gateway conversion cassette (Thermo Fisher); the resulting destination vector was named pDESTDV3. NRG cDNAs were transferred by Gateway recombination from their respective entry vectors (see below).

$N R G$ expression constructs. Sequences for NRG1 cDNAs were of mouse origin and encoded $\beta 1 \mathrm{a}$ isoforms. A cDNA for human NRG2 ( $\beta$ isoform; IMAGE:100066341; GenBank accession number BC166615.1) was obtained from Origene Technologies. Mouse NRG3 (transcript variant 1; GenBank accession number NM_008734.3) was cloned by RT-PCR from brain total RNA. All NRG1 constructs and NRG3 were initially cloned into pENTR/D; the NRG2 construct was in pENTR223.1 (both Thermo Fisher). Unless indicated otherwise, all constructs harbored a V5 epitope tag upstream of the EGF-like domain that does not interfere with function, as described previously (Wang et al., 2001). Mutated variants of NRG, such as deletions, replacements, fusions, and point mutations, were generated by replacing the wild-type sequence with synthetic DNA fragments ("gBlocks") harboring the desired alteration (Integrated DNA 
Technologies). NRG open reading frames were transferred by Gateway recombination to pDESTDV3 (for attenuated expression following cationic lipid-mediated transfection) or to pAAV_hSynI (for neuronselective gene expression under the control of the human Synapsin I promoter following adeno-associated virus [AAV]-mediated transduction).

Mouse monoclonal antibody against Type II NRG1. To generate the immunogen, the nucleotide sequence encoding the 469 residue extracellular domain of mouse Type II NRG1 was subcloned into Bacmid vector pFastBac1 (Thermo Fisher), with a hexahistidine tag motif added to its $3^{\prime}$ end to aid in affinity purification. Bioactive Type II NRG1 ectodomain was purified by metal affinity chromatography from $5 \mathrm{~L}$ of insect cell medium conditioned by Sf9 cells infected with Type II NRG1-ECD baculovirus (Genscript). Protein integrity and biological activity were validated by SDS-PAGE, Western blotting, and assaying ErbB receptordependent Erk pathway activation in HEK293 cells. Recombinant Type II NRG1-ECD was then used to immunize SJL mice and to develop mouse monoclonal anti-NRG1 antibody 7C11 (hybridomas generated at Precision Antibodies). Clone 7C11 was validated for use in immunocytochemistry and in immunohistology (see Fig. 3) but was found not to work in Western blotting.

Rabbit polyclonal antibody against NRG3. Polyclonal rabbit antiserum 1352 was raised against a peptide corresponding to amino acid residues 690-709 of mouse NRG3 (accession number: NP_032760.1). The peptide included an amino-terminal cysteine for conjugation to keyhole limpet hemocyanin. The antiserum was validated to selectively recognize NRG3, but not NRG1 or NRG2, by Western blotting and immunocytochemistry of HEK293 cells transfected with corresponding expression constructs.

Preparation of adeno-associated viruses. AAV-293 cells (Agilent), grown in DMEM with $10 \%$ FBS, were used for AAV production. Cells between passage 3-5 were seeded in $10 \mathrm{~cm}$ dishes and transfected at $50 \%-60 \%$ confluence with pHelper (Agilent), pAAV-RC1 (Cell Biolabs), and recombinant pAAV vectors under the control of the human Synapsin I promoter (pAAV_hSynI). Medium was changed $2 \mathrm{~h}$ before transfection. For each dish, $4 \mu \mathrm{g}$ of plasmid DNAs (1:1:1 mass ratio) were first mixed $1: 4$ with polyethyleneimine $(1 \mathrm{mg} / \mathrm{ml})$ in $500 \mu$ l of OptiMEM medium (Thermo Fisher) and then added to the cells. Following transfection $(72 \mathrm{~h}$ ), cells were scraped into gradient buffer ( $150 \mathrm{~mm} \mathrm{NaCl}, 10$ $\mathrm{mm} \mathrm{MgCl}_{2}, 10 \mathrm{~mm}$ Tris-Cl, pH 7.6) and lysed by multiple freeze-thaw cycles. The lysate was cleared by centrifugation, and the supernatant was layered on top of an iodixanol step gradient (15\%, 25\%, 40\%, and 58\% $(\mathrm{v} / \mathrm{v})$ in gradient buffer); the remaining volume was filled with gradient buffer. Ultracentrifugation was done at $48,000 \mathrm{rpm}$ using a Type $70 \mathrm{Ti}$ fixed angle rotor (Beckman) for $2 \mathrm{~h}, 18^{\circ} \mathrm{C}$. Viral particles were collected from the $40 \%$ iodixanol layer and stored at $4{ }^{\circ} \mathrm{C}$ for immediate use or at $-80^{\circ} \mathrm{C}$ for long-term storage. AAV preparations were initially tested on cultured hippocampal neurons and used at dilutions that yielded widespread expression at moderate levels suitable for detection by Western blotting.

Cell culture. Dissociated hippocampal neurons were prepared from E19 Sprague Dawley rat pups and propagated in defined medium, as described previously (Brewer et al., 1993). Neurons were plated on polyD-lysine-coated plastic for Western blotting, or on poly-D-lysine-coated coverslips for immunofluorescence cytochemistry. Neurons were maintained in defined Neurobasal/B27 medium (Thermo Fisher), and half of the medium was changed once every week. To achieve sparse expression for immunofluorescence cytochemistry of dual-pass NRGs, neurons were transfected between DIV 8-10 with $1.5 \mu \mathrm{g}$ of plasmid DNA per well of a 24-well plate using Lipofectamine 2000 (Thermo Fisher). pDESTDV3-based plasmids expressing NRG under the control of the attenuated CMV promoter (see above) and GFP under the control of the human Synapsin I promoter were mixed 1:1 (mass ratio) for double transfections or 1:1:1 for triple transfections. For other ICC experiments and Western blotting, neurons were transduced with AAV at least 1 week before analysis. HEK2 23 cells were propagated at $37^{\circ} \mathrm{C}$ and $5 \% \mathrm{CO}_{2}$ in DMEM supplemented with 10\% FBS (Thermo Fisher), and transfected with $1.5 \mu \mathrm{g}$ plasmid DNA per well of a 24 -well plate using Xtreme HP transfection reagent (Roche). For competition experiments, neurons were transfected at DIV 8 and treated daily for $48 \mathrm{~h}$ with $60 \mathrm{~nm}$ NRG1 EGF-like domain (Shenandoah Biotechnology).

Semiquantitative RT-PCR. Total RNA was extracted from whole brains of E19, P7, and adult Sprague Dawley rats using Tri Reagent solution (Thermo Fisher). Aliquots of RNA $(1 \mu \mathrm{g})$ were reverse transcribed at $55^{\circ} \mathrm{C}$ for $20 \mathrm{~min}$ using random hexamer primers and Superscript IV reverse transcriptase (Thermo Fisher). For semiquantitative PCR, reverse transcription reactions were diluted 10 -fold in water, and $1 \mu \mathrm{l}$ aliquots of the diluted samples were amplified in $20 \mu \mathrm{l}$ total volume using FastStart DNA Master SYBR Green reagent mix (Roche) and $0.5 \mu \mathrm{M}$ of the following NRG1 type-specific forward primers: Type I, 5' -GGA AGG GCA AGA AGA AGG AC-3'; Type II, 5' -TTG TGC AAG CGG TGC GCA CTG-3'; and Type III (CRD-NRG1), 5' -CAT TCT GGC TTG CCT AGT CAG C- $3^{\prime}$. The sequence of the common reverse primer was $5^{\prime}$-CCA GTC GTG GAT GTT GAT GTG-3'. For normalization, $\beta$-actin transcripts were amplified using the following primers: $\beta$-actin forward, $5^{\prime}$-ACC AAC TGG GAC GAT ATG GAG AAG A-3', $\beta$-actin reverse, $5^{\prime}$-CGC ACG ATT TCC CTC TCA GC-3' (Peirson et al., 2003). Annealing temperatures were $60^{\circ} \mathrm{C}$ for NRG1 targets and $55^{\circ} \mathrm{C}$ for $\beta$-actin. Amplification was done in a LightCycler 1.5 (Roche), and the results were analyzed using LightCycler software version 4.05. Values for NRG1 Types I-II, CRD-NRG1 targets, and the $\beta$-actin reference were internally calibrated using plasmid DNA standards.

Double ISH. We used RNAscope, a fluorescence-based multiplexing ISH technique (Wang et al., 2012), to analyze expression of Type II NRG1 mRNA in the mouse brain. Briefly, $12 \mu \mathrm{m}$ fresh-frozen sagittal sections from 4-week old wild-type mice were hybridized at $40^{\circ} \mathrm{C}$ for $2 \mathrm{~h}$ with specific probe sets for mouse Type II NRG1 and Gad1. Probes were as follows: NRG1, accession number XM_006509059.2, target region 66257529; Gad1: accession number NM_008077.4, target region: 62-3113. Specific hybridization signals were amplified following the manufacturer's instructions, and detected with Atto 550 (for Type II NRG1) and Atto 647 (for Gad1) fluorophores. Sections were additionally labeled with DAPI to visualize nuclei.

Type II NRG1 ectodomain purification from conditioned medium. Cultured hippocampal neurons in 6-well plates were transduced at DIV 15 with AAV-expressing Type II NRG1/V5 and assayed at DIV 23. To reduce baseline Type II ectodomain levels in the conditioned medium, cells were first washed into conditioned medium from untransduced hippocampal neurons. Following treatments, the Type II ectodomain was captured from $1 \mathrm{ml}$ supernatant using heparin-agarose beads (Sigma). Beads were first equilibrated with cold Neurobasal/B27 and then incubated for several hours at $4^{\circ} \mathrm{C}$ with conditioned medium. Following three washes with cold PBS, heparin-bound protein was eluted with $40 \mu \mathrm{l}$ SDS-PAGE sample buffer (Pierce); $15 \mu$ l aliquots were analyzed by Western blotting using anti-V5.

Western blotting. Protein samples from cultured cells were sizefractionated on $4 \%-15 \%$ Mini-Protean TGX precast gels (Bio-Rad) and electroblotted onto nitrocellulose. Membranes were blocked with 3\% BSA in Tris-buffered saline (TBS) containing 0.1\% Tween 20 (TBS/T), and incubated with primary antibodies in blocking solution for several hours at room temperature or overnight at $4^{\circ} \mathrm{C}$. After several washes with TBS/T, membranes were incubated with HRP-conjugated secondary antibodies (Jackson ImmunoResearch Laboratories) for $1 \mathrm{~h}$ at room temperature. Signals were detected by chemiluminescence using a ChemiDoc MP imager (Bio-Rad) and quantified using Image Laboratory software (Bio-Rad).

Immunofluorescence cytochemistry. Neurons or HEK 293 cells grown on round $12 \mathrm{~mm}$ glass coverslips were fixed for $15 \mathrm{~min}$ at room temperature in $4 \%$ PFA in PBS supplemented with $4 \%$ sucrose. After extensive washing with PBS, cells were blocked and permeabilized with $10 \%$ normal goat serum $/ 0.1 \%$ TX-100 in PBS. For surface labeling, blocking solution without detergent was used. Cells were incubated with primary antibody for several hours at room temperature or overnight at $4^{\circ} \mathrm{C}$ with gentle rocking, and for $1 \mathrm{~h}$ with donkey or goat secondary antibodies conjugated to AlexaFluor-488, DL-549 and Alexa-647 fluorophores (Thermo Fisher or Jackson ImmunoResearch Laboratories). DAPI stain was included to label nuclei (Thermo Fisher). Coverslips were washed with PBS, dipped in water, and 


\section{A Attenuated CMV:}

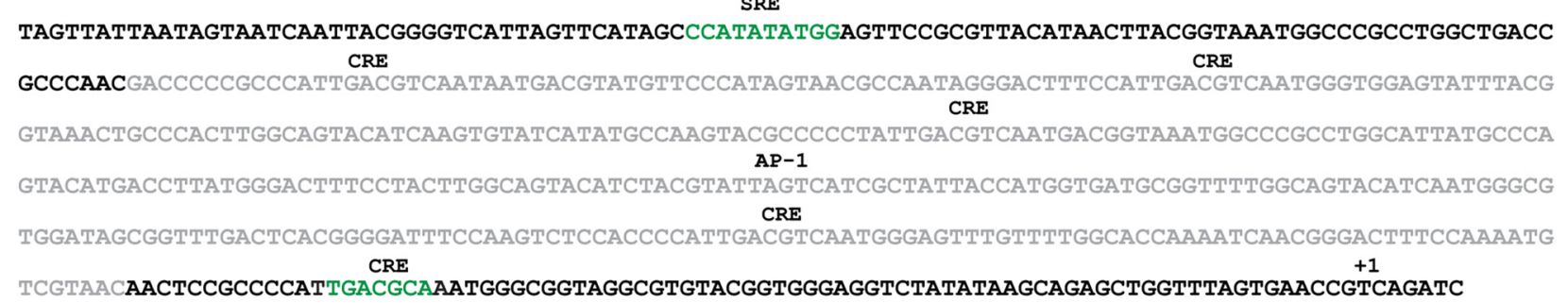

B

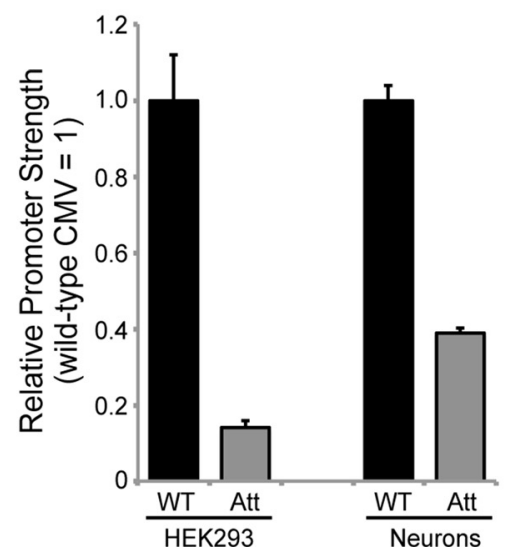

C Wild-type CMV

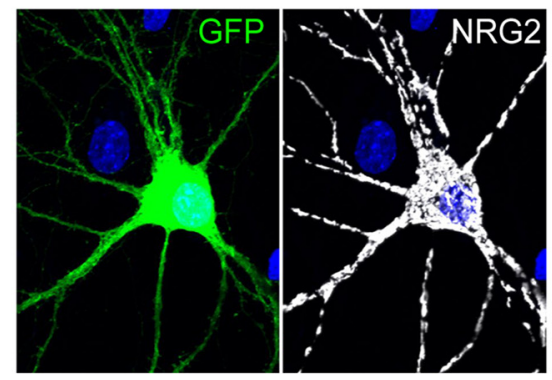

Attenuated CMV (pDESTDV3)

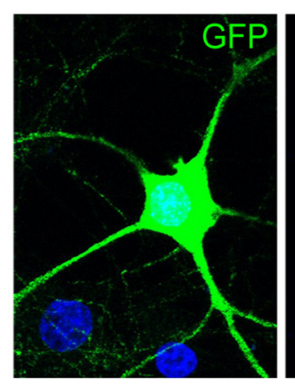

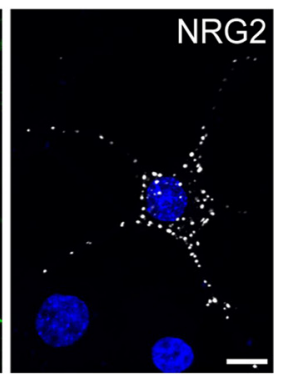

Figure 1. Generation and characterization of an attenuated CMV promoter to drive low to moderate NRG expression in cultured neurons. $A$, Sequence of the attenuated CMV promoter. Bases shown in gray were removed. Locations of numerous cAMP response elements (CRE), a serum response element (SRE), and an AP- 1 binding site that drive transcription, as well as the transcription initiation site (1), are indicated. $\boldsymbol{B}$, Transcriptional activity was measured in HEK293 cells and in cultured hippocampal neurons cotransfected with reference plasmid pRL-TK (Promega) and either wild-type (WT) or attenuated (Att) CMV reporter constructs harboring firefly luciferase. Data are normalized to WT CMV and indicate the mean \pm SEM of 3 (HEK293) or 4 (neurons) independent experiments run in triplicates (HEK 293) or duplicates (neurons). C, Subcellular distribution of NRG2 protein in hippocampal neurons transfected with constructs for GFP under the control of the Synapsin I promoter and for NRG2 under the control of the WT CMV promoter (left) or the attenuated CMV promoter (right). Signals were detected with NRG2 antibody mAB11. Immunoreactivity is widespread and blotchy in the neuron transfected with the WT CMV construct, whereas it is punctate and limited to the cell body and proximal neurites in the neuron transfected with the attenuated CMV construct. Scale bar, $10 \mu \mathrm{m}$.

mounted on slides using Mowiol/DABCO (1,4-diazabicyclo-[2,2,2]octane) mounting medium.

Preembedding immunogold electron microscopy. DIV 21 cultured hippocampal neurons transduced with AAV expressing Type II NRG1/V5 were fixed for 15 min with 4\% PFA in PBS with 4\% sucrose, then washed and blocked with $5 \%$ normal goat serum for $40 \mathrm{~min}$. Cells were incubated with mouse monoclonal anti-Type II NRG1 clone 7C11 and secondary antibodies (Nanogold, Nanoprobes) for $1 \mathrm{~h}$, fixed with $2 \%$ glutaraldehyde in PBS overnight, silver enhanced (HQ kit, Nanoprobes), treated with $0.2 \%$ osmium tetroxide in $0.1 \mathrm{M}$ phosphate buffer $(\mathrm{PB})$ at $\mathrm{pH} 7.4$ for $30 \mathrm{~min}$, en bloc stained with $0.25 \%$ uranyl acetate in acetate buffer at $\mathrm{pH}$ 5.0 for $1 \mathrm{~h}$, dehydrated in graded ethanols, and embedded in epoxy resin. Thin sections were examined on a JEOL 1200 EX transmission electron microscope and images collected with a digital CCD camera (AMT XR100, Advanced Microscopy Techniques).

Immunofluorescence histochemistry. Rats $(\sim \mathrm{P} 30)$ were transcardially perfused with $4 \%$ PFA in $0.1 \mathrm{~m}$ PBS, pH 7.4. Brains were postfixed overnight in the same fixative, and $50 \mu \mathrm{m}$ sections were cut on a vibratome. Sections were blocked in 10\% normal donkey serum, $0.25 \%$ Triton $\mathrm{X}-100$ in $0.1 \mathrm{M} \mathrm{PB}$ for $1 \mathrm{~h}$ at room temperature and incubated with primary antibodies in $0.1 \mathrm{M} \mathrm{PB}$ with $5 \%$ normal donkey serum and $0.25 \%$ Triton X-100 (dilution buffer) for $24 \mathrm{~h}$ at $4^{\circ} \mathrm{C}$ with gentle rocking. Slices were washed in $0.1 \mathrm{M}$ PB with $0.25 \%$ Triton X-100 for at least $30 \mathrm{~min}$ before incubation with fluorophore-conjugated donkey secondary antibodies for $90 \mathrm{~min}$ at room temperature in dilution buffer. DAPI stain was included to label nuclei. After extensive washes in PBS with $0.25 \%$ Triton $\mathrm{X}-100$, sections were mounted on gelatin-coated slides, dried, and mounted in Mowiol-DABCO.

Microscopy and image analyses. Fluorescence signals were analyzed by confocal microscopy using LSM780 or LSM710 microscopes (Carl
Zeiss). For cultured cells, images were acquired at $63 \times$ magnification. Image stacks were projected in the $Z$ dimension using the maximum intensity method. For tissue, including RNAscope and immunocytochemistry, images were acquired at $20 \times$ or $40 \times$ magnification and tiled at $10 \%$ overlap. Images were adjusted for overall brightness and contrast using ImageJ. For all quantitative analyses, images were acquired under nonsaturating conditions. To evaluate axonal accumulation of NRG3 puncta in neurons transfected with NRG3/V5, GFP-SNPH $\Delta$-MTB, and mCherry, regions of interest (ROIs) were selected based on the presence of NRG3/V5 puncta. Images were then acquired for NRG3, GFP$\mathrm{SNPH} \Delta-\mathrm{MTB}$, and mCherry, and the fraction of NRG3 puncta on neurites that were positive for both GFP-SNPH $\Delta$-MTB and mCherry was calculated using the "colocalization" function included in the ZEN software (Carl Zeiss). The same function was also used to analyze the extent of colocalization of NRG3/CRD-NRG1 puncta with the presynaptic marker bassoon and the postsynaptic glutamatergic marker PSD-95. Time course of NRG3/CRD-NRG1 puncta formation and colocalization with endogenous ErbB4 in transfected neurons was analyzed with Volocity software (PerkinElmer). All quantitative data are based on analyses of at least 10 ROIs from three separate experiments.

Statistics. One-way ANOVA for independent measurements was used to analyze the effects of protease inhibition on Type II NRG1 ectodomain shedding (see Fig. 6) and to assess the extent of colocalization of CRDNRG1 and NRG3 with synaptic markers. $p$ values for multiple comparisons were calculated using Dunnett's (see Fig. 6) or Tukey's (see Fig. 8) post hoc test. All other experiments that were not statistically analyzed were independently repeated a minimum of 3 times to ensure consistency and reproducibility. 
A

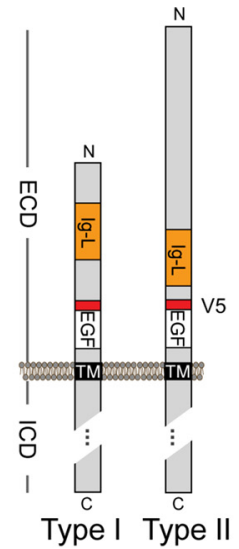

B

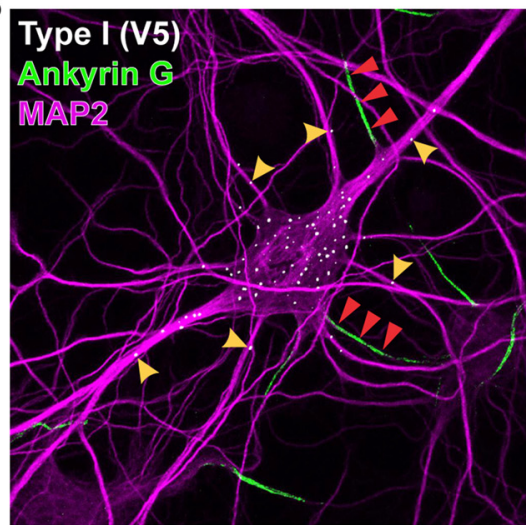

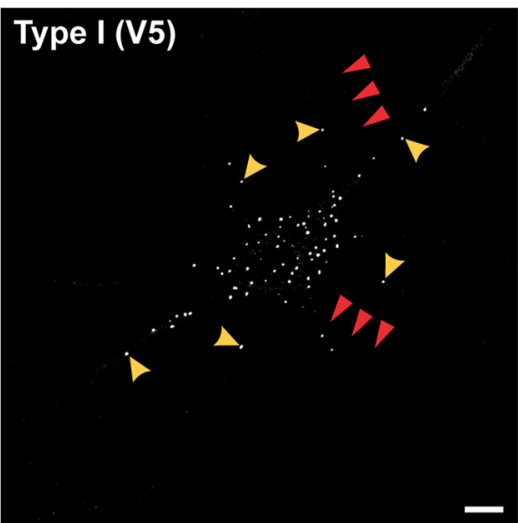

C
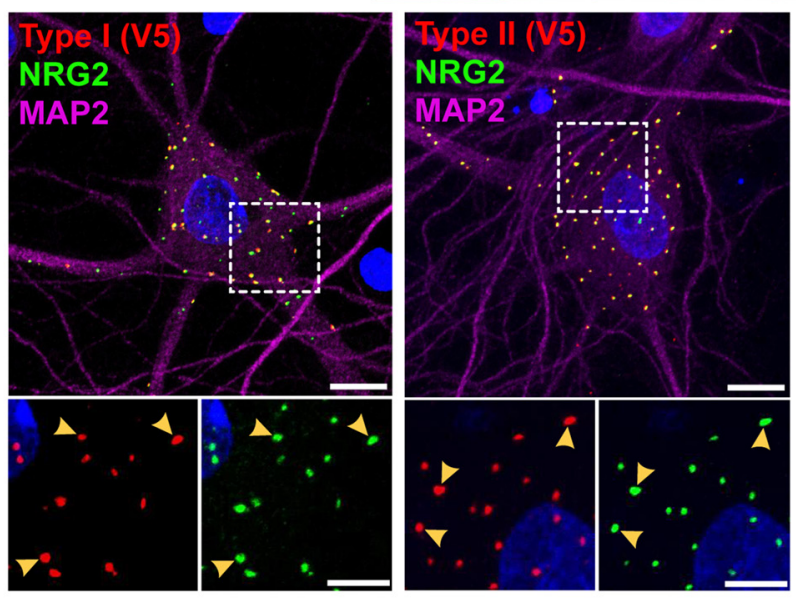

$\mathbf{F}$

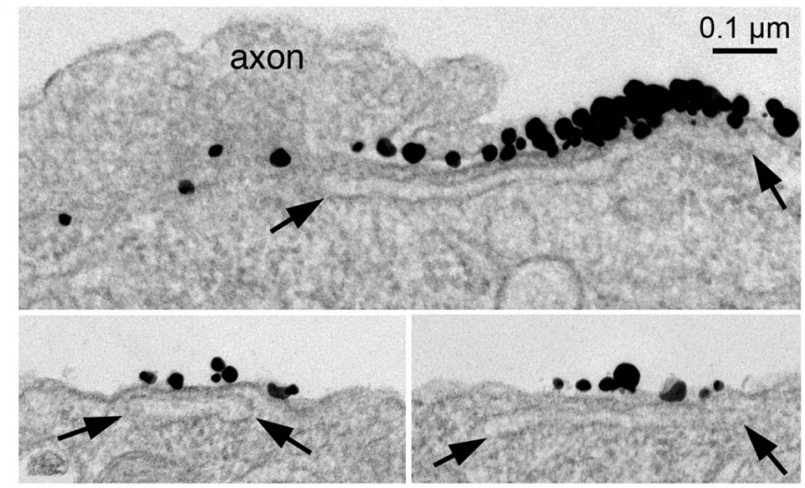

D NRG1 (V5)

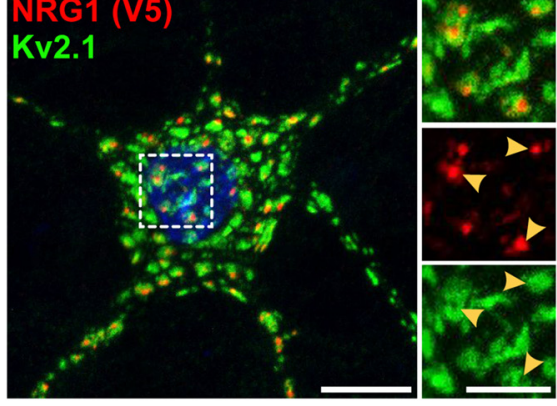

E

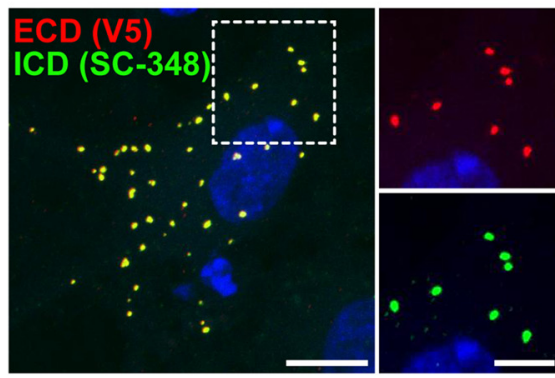

G
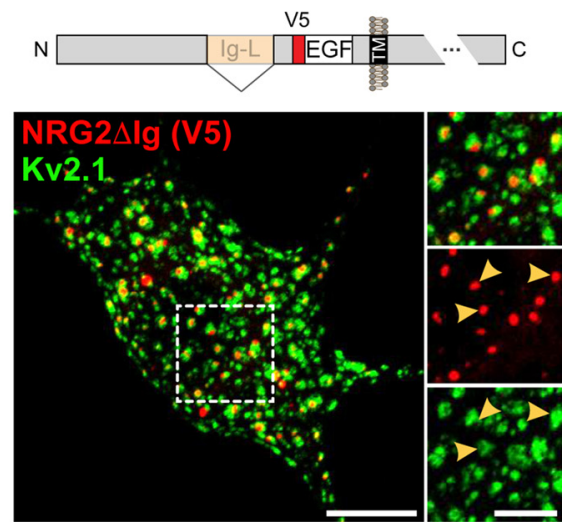

Figure 2. Ig-NRG1s accumulate on cell bodies and proximal dendrites in cultured hippocampal neurons. $A$, Schematic diagram of V5 epitope-tagged Type I and II NRG1 $\beta 1$ a constructs used to analyze subcellular expression of Ig-NRG1s. B, Representative low-magnification confocal image of a neuron transduced with an AAV expressing Type I NRG1/V5, showing V5-immunoreactive puncta concentrated on the cell body and proximal MAP2-positive dendrites (yellow arrowheads), but not on distal dendrites or proximal axons identified by Ankyrin $G$ staining (red arrowheads). C, Colocalization of endogenous NRG2 (mAB11) with Type I-NRG1/V5 (left) or Type II-NRG1/V5 (right) in AAV-transduced hippocampal neurons; neuronal morphology was revealed by MAP-2 staining. ROls are shown at higher magnification (bottom). Arrowheads indicate examples of overlapping puncta. D, As previously reported for NRG2 (Vullhorst et al., 2015 ), NRG1 Type II puncta (arrowheads) are embedded in large clusters of Kv2.1 that likely correspond to SSCS. E, Extensively overlapping pattern of ECD and ICD signals for Type I NRG1, visualized with anti-V5 and the carboxyl-terminal antibody SC-348, indicate that Ig-NRG1 puncta are comprised of unprocessed protein. F, Immunogold EM images using antibody 7C11 against the ECD of Type II NRG1 (Fig. 3), showing label on the external side of the neuronal plasma membrane atop SSCs (open sacs indicated by arrows). Top, Axon without label in close contact and a highly concentrated patch of label immediately adjacent to the axon/soma contact area. Bottom, Labeled areas of the neuronal soma without any cellular processes in contact. G, The spatial relationship between Kv2.1 clusters and NRG2 puncta (arrowheads) is maintained in the absence of the Ig-like domain. Top, Schematic illustration of mutant NRG2 lacking the lg-like domain (NRG2 $\Delta \mathrm{lg} / \mathrm{V} 5)$. Bottom, Double immunofluorescence of V5-tagged NRG2 $\Delta \mathrm{lg}$ and Kv2.1. Examples of coclusters are marked by arrowheads in the magnified single-channel ROI (right). All images are rendered as Z-stack projections. DAPI was included to label nuclei. Scale bars: main images, $10 \mu \mathrm{m} ; \mathrm{ROls}, 5 \mu \mathrm{m}$. 

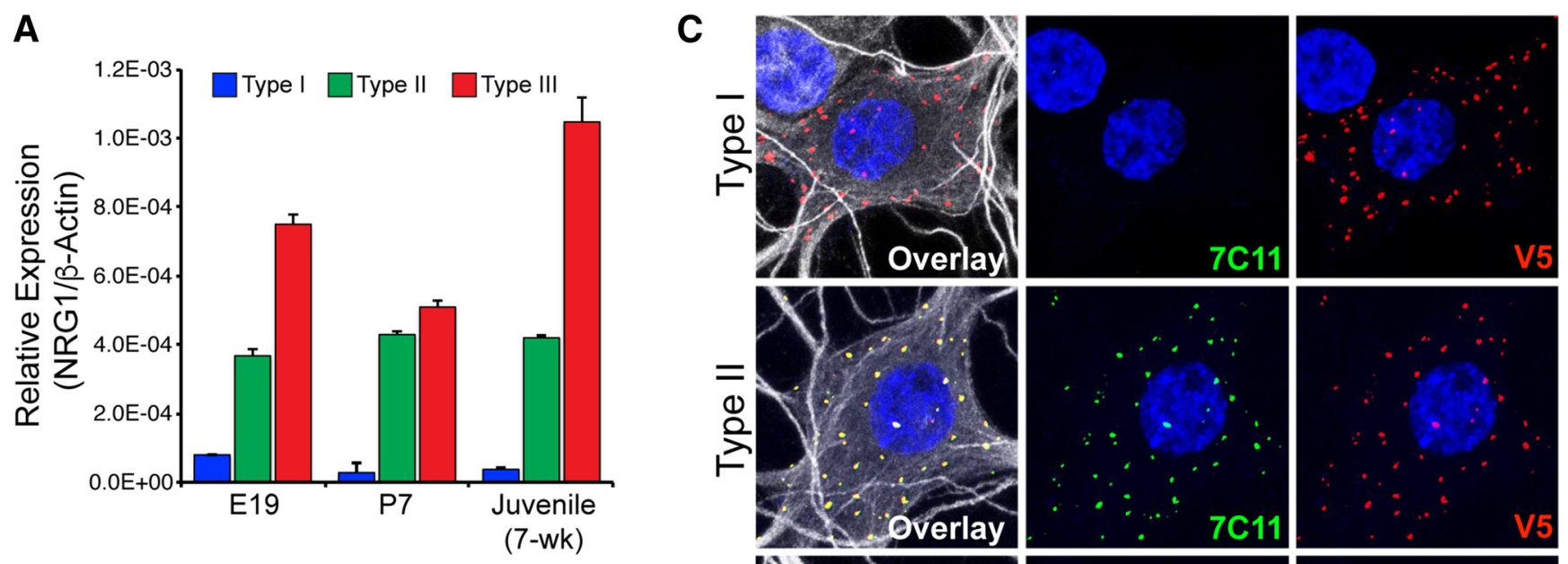

B
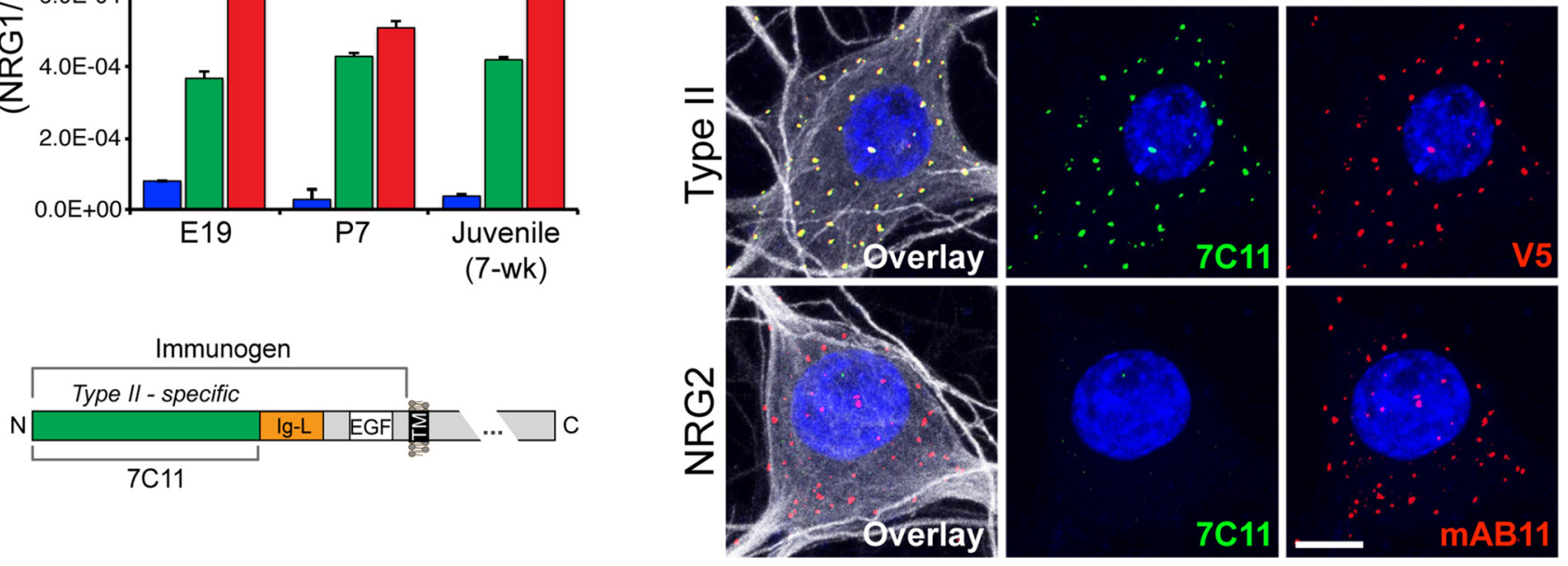

Figure 3. Generation of a mouse monoclonal antibody against Type II NRG1. A, Semiquantitative RT-PCR of NRG1 Types I, II, and III (CRD-NRG1 or SMDF) from E19 fetuses, P7 pups, and adult rat total brain RNA. Data were normalized to $\beta$-actin. Data points indicate mean \pm SEM of three independent RNA samples, each run in duplicates. $B$, Schematic illustration of the generation of mouse monoclonal antibody 7C11 against the Type II NRG1 ECD (see Materials and Methods). C, Clone 7C11 selectively recognizes the NRG1 Type II ECD, as demonstrated by its reactivity toward Type II (middle), but not toward Type I NRG1 (top) in AAV-transduced hippocampal neurons, or endogenous NRG2 (bottom); MAP2 (white) was included in the overlay images to reveal neuronal morphology. Based on the lack of cross-reactivity of clone 7C11 with Type I NRG1, the 7C11 epitope is likely located in the Type Il-specific sequence shown in green (B). Images are Z-stack projections. Scale bar, $10 \mu \mathrm{m}$.

\section{Results}

Single-pass NRG1 proforms accumulate on neuron cell bodies in vitro and in vivo

Earlier observations with NRG2 indicated that the use of strong viral promoters causes ectopic accumulation in axons and distal dendrites (Vullhorst et al., 2015). Because ISH studies indicate that NRG mRNAs are generally expressed at low to moderate levels in the postnatal brain (Corfas et al., 1995; Longart et al., 2004), we developed an attenuated CMV promoter to better reproduce the subcellular distribution of endogenous NRGs under these conditions (Fig. 1; see Materials and Methods). The corresponding expression vector (referred to as pDESTDV3) was used for all NRG transfections. We then generated constructs for mouse Ig-NRG1 Types I and II that included a V5 epitope tag immediately upstream of the EGF-like domain (Fig. 2A), a location that does not interfere with NRG function (Wang et al., 2001). Of note, the sequences of all NRG1 constructs used in this study, including CRD-NRG1, harbored the $\beta 1$ a sequence downstream of the EGF-like domain. Reminiscent of the subcellular distribution of NRG2 (Vullhorst et al., 2015), hippocampal neurons cotransfected with GFP and Ig-NRG1s harbored numerous puncta confined to cell bodies and proximal MAP2-positive dendrites, but absent from distal dendrites or Ankyrin G-positive axons, as illustrated for Type I NRG1 in Figure 2B. To confirm that Ig-NRG1s and NRG2 share the same subcellular localization, hippocampal neurons were transduced with Type I or Type II NRG1/V5-harboring AAVs that were titrated to drive low-level gene expression (Fig. 1C). Neurons were labeled with antibodies against V5 and NRG2 to reveal somatic clusters of endogenous pro-NRG2 present on ErbB4-positive GABAergic interneurons (Vullhorst et al., 2015). Indeed, signals for both Type I and Type
II NRG1 overlapped extensively with endogenous pro-NRG2 (Fig. 2C), and colocalized with Kv2.1 clusters (Fig. 2D). Furthermore, colabeling of the extracellular and intracellular domains indicated that somatic Ig-NRG1 puncta are comprised of their respective unprocessed proforms (Fig. 2E). Last, immunogold EM analysis of AAV-transduced neurons confirmed that Type II NRG1/V5 clusters were located on cell somata atop SSCs, as previously shown for NRG2 (Vullhorst et al., 2015), but absent from presynaptic terminals (Fig. $2 F$ ).

The Ig-like domain enables NRGs to bind heparan sulfate proteoglycans, and this interaction is thought to promote local retention of the ectodomain in the extracellular matrix upon shedding (Loeb and Fischbach, 1995). To determine whether the Ig-like domain is also involved in trafficking, we generated AAVs harboring a mutant NRG2 lacking the Ig-like domain (NRG2 $\Delta \mathrm{Ig} / \mathrm{V} 5$ ). As shown in Figure 2G, V5 immunoreactivity in transduced hippocampal neurons was punctate, concentrated on cell bodies, and reproduced the spatial relationship of endogenous NRG2 with Kv2.1 channel clusters, indicating that the Ig-like domain is not required to target NRGs to SSC-type membrane contacts.

We sought to corroborate these findings in vivo by analyzing the subcellular distribution of endogenous Ig-NRG1s in the adult rodent brain. However, because in our hands commercially available isoform-specific antibodies against Ig-NRG1s were not useful for immunohistochemistry, we set out to generate a custom antibody. Toward this goal, we first used semiquantitative RTPCR to determine which Ig-NRG1 isoform is most abundantly expressed in the rodent brain by measuring Type I and Type II NRG1 mRNA levels in whole-brain RNA preparations from E19, P7, and adult rats by semiquantitative real-time RT-PCR. As shown in Figure $3 A$, at all three time points, $\beta$ actin-normalized 


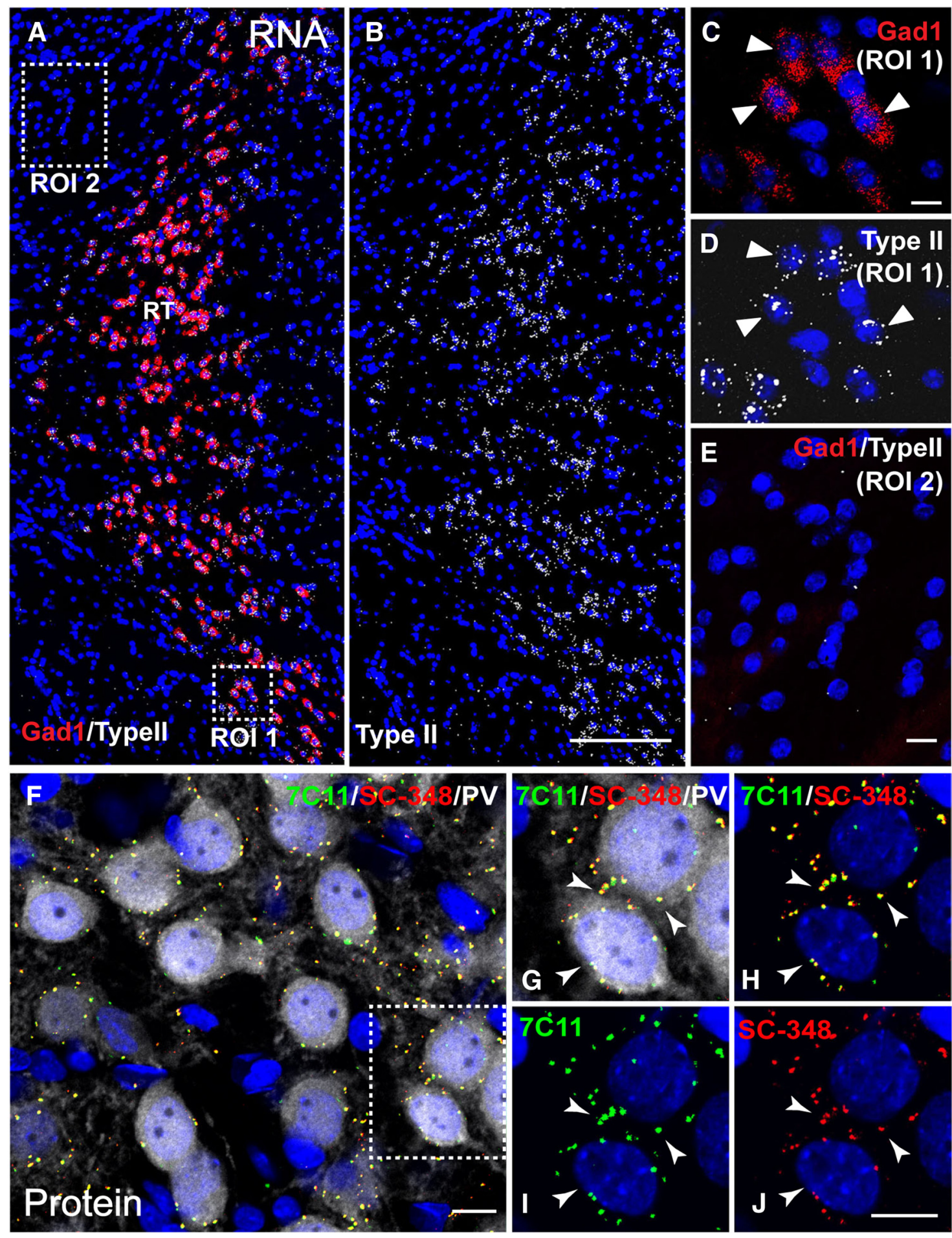

Figure 4. Type II NRG1 mRNA and protein are expressed in GABAergic neurons of the RTN. $\boldsymbol{A}-\boldsymbol{E}$, Double-fluorescence ISH with RNAscope probes for Type II NRG1 and Gad1 in a representative coronal mouse section through the RTN. Low-magnification image showing overlays for both Type II NRG1 and Gad1 ( $\boldsymbol{A}$ ), or only Type II NRG1 (B), reveals strong Type II expression in numerous GABAergic neurons. $\boldsymbol{A}$, Boxed ROI 1 is magnified in $\boldsymbol{C}, \boldsymbol{D}$. Arrowheads indicate examples of neurons coexpressing Type II NRG1 and Gad1 mRNA. Boxed ROI 2 outside the RTN is magnified in $\boldsymbol{E}$ to emphasize the lack of Gad1 and negligible NRG1 label. $\boldsymbol{F}$-J, Triple immunofluorescence histochemistry of Type II NRG1 protein in adult mouse RTN neurons using antibodies against its ECD (7C11) and ICD (SC-348). $\boldsymbol{F}$, Overlay shows numerous NRG puncta (colabeled with 7C11 and SC-348) on or near cell bodies of PV-positive GABAergic neurons. Boxed ROl is magnified in $\mathbf{G}-J$ to illustrate the extensive overlap between ECD and ICD signals (arrowheads). DAPI is included in all images to label nuclei. Scale bars: $A, B, 200 \mu \mathrm{m} ; C-J, 10 \mu \mathrm{m}$.

Type II NRG1 transcript levels were higher than Type I NRG1 (E19: 4.7-fold; P7: 15.4-fold; adult: 11.2-fold), indicating that Type II NRG1 is a major Ig-NRG1 in the perinatal and adult brain, consistent with previous studies (Meyer and Birchmeier, 1994; Liu et al., 2011). Unlike Type II-NRG1 mRNA levels that remain relatively constant across the tested time points, CRD-NRG1 expression increases postnatally to become the predominant isoform (Fig. $3 A$ ). Hence, Type II and Type III NRG1 are the most abundant NRG1 isoforms in the adult rat brain. 

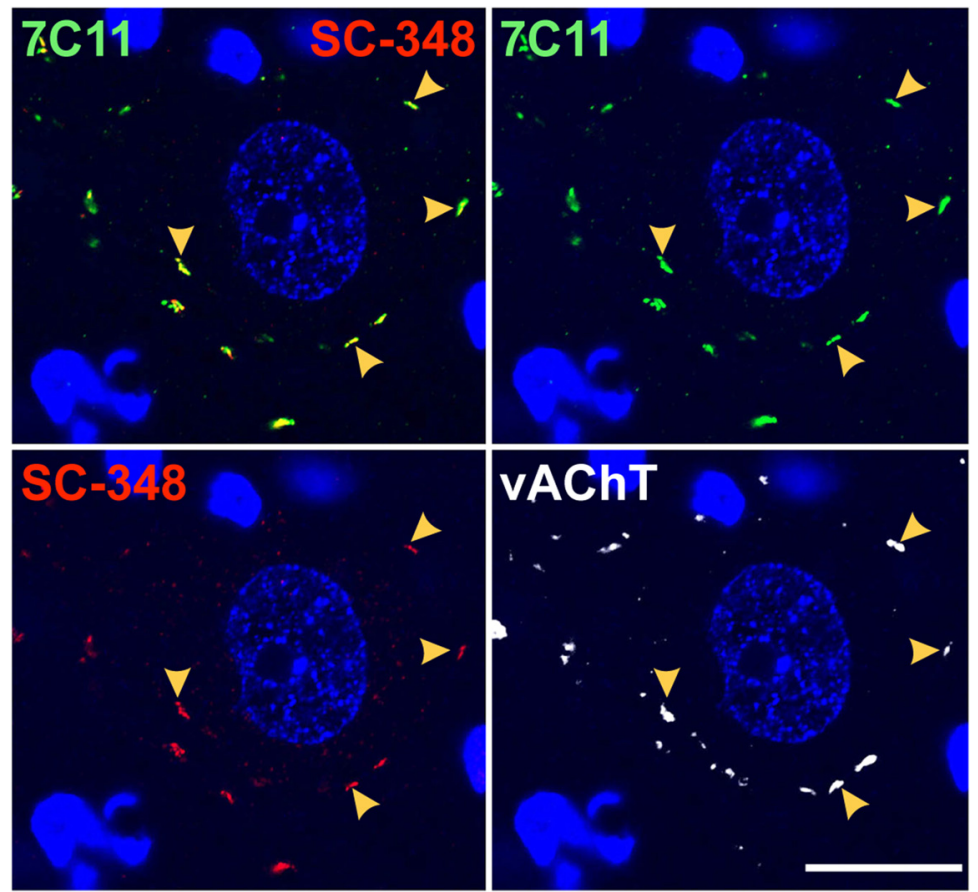

Figure 5. NRG1 Type II protein accumulates at spinal chord C-boutons. Triple immunofluorescence histochemistry of Type II NRG1 protein in adult mouse spinal chord $\alpha$-motorneuron cell bodies using antibodies against Type II NRG1 ECD (7C11) and ICD (SC-348), as well as the vAChT to identify cholinergic (-boutons. Arrowheads indicate examples of Type II NRG1 puncta at C-boutons labeled with both 7C11 and SC-348 that likely represent unprocessed pro-NRG1 at SSCs. Scale bar, $20 \mu \mathrm{m}$.

To analyze the expression and subcellular distribution of endogenous Type II NRG1 protein, we developed mouse monoclonal antibody 7C11 against its ECD (Fig. 3B; for further details, see Materials and Methods). In cultured hippocampal neurons transduced with AAVs harboring Type I or Type II NRG1, clone 7C11 detected Type II NRG1 but not Type I NRG1 (Fig. 3C). Furthermore, 7C11 did not cross-react with NRG2 (Fig. 3C, bottom), the closest structural homolog of Type II NRG1, suggesting that the antibody selectively binds to an epitope in the unique amino-terminal region of Type II NRG1 (Fig. 3B). We then used clone 7C11 to investigate the subcellular expression pattern of Type II NRG1 in the reticular nucleus of the thalamus (RTN), where our fluorescence-based ISH (RNAscope) experiments identified robust mRNA expression in Gad1-positive GABAergic neurons but not in adjacent Gad1-negative cells (Fig. 4A-E); this pattern is consistent with an earlier study using a radioactively labeled Iglike domain ISH probe (Corfas et al., 1995). Coimmunofluorescence histochemistry of Type II NRG1 protein in the RTN with clone 7C11 and anti-ICD antibody SC-348, which recognizes all NRG1 isoforms with a long (a-type) cytoplasmic tail, revealed numerous overlapping puncta on parvalbumin (PV)-positive GABAergic neuron cell bodies that were absent in adjacent PVnegative cells (Fig. $4 F-J$ ). This punctate labeling pattern of endogenous Type II NRG1 in RTN neurons is consistent with the distribution of heterologously expressed Type II NRG1 in cultured hippocampal neurons (Figs. 2C, 3C). Using the panNRG1 antibody SC-348, Gallart-Palau et al. (2014) recently reported NRG1 puncta atop postsynaptic SSCs at cholinergic C-bouton synapses. We therefore performed tripleimmunofluorescence histochemistry of rat spinal cord crosssections with clone 7C11, SC-348 and anti-vAChT, and confirmed overlapping punctate signals with both NRG1 antibodies that colocalized with vAChT (Fig. 5). This finding demonstrates that Type II NRG1 targets to C-bouton synapses and is consistent with the general notion that IgNRGs accumulate at SSC-type ER-PM contacts.

\section{NMDA receptor activity regulates Ig-NRG1 processing and ectodomain release}

The colocalization of ECD and ICD signals for Type I NRG1 shown in Figure 2E and for Type II NRG1 shown in Figures 4 and 5 suggested that clustered Ig-NRG1s accumulate as unprocessed proteins. Consistent with this notion, Western blot analysis of lysates from hippocampal neurons transduced with AAVs harboring Type I and Type II NRG1 using anti-ECD (V5) and anti-ICD (SC-348) antibodies revealed that their unprocessed proforms account for the bulk of immunoreactivity (Fig. 6A,B). Furthermore, a $20 \mathrm{~min}$ incubation with $20 \mu \mathrm{m}$ glutamate greatly reduced proform band intensities in an NMDA receptor-dependent manner (i.e., AP5-sensitive; $100 \mu \mathrm{M}$ ) and increased band intensities of their respective processed ECD and ICD fragments. To directly demonstrate glutamate-dependent ectodomain shedding, we exploited the affinity of the Ig-like domain for heparin to concentrate Type II NRG1 from conditioned supernatants of AAV-transduced hippocampal neurons expressing V5-tagged Type II NRG1. To reduce baseline levels resulting from ongoing NMDAR activity, cell culture medium was changed immediately before treatment. After pull-down with heparin-agarose beads, the $\sim 60 \mathrm{kDa}$ Type II NRG1 ectodomain was detected by Western blot using anti-V5. Compared with untreated controls, Type II NRG1 ectodomain levels increased twofold following a $20 \mathrm{~min}$ treatment with $20 \mu \mathrm{M}$ glutamate (Fig. 6C,D). This increase of ectodomain shedding in response to glutamate was abolished by pretreatment of neurons with AP5. Next, we investigated the role of matrix metalloproteinases and BACE that could function downstream of NMDAR activation. As shown in Figure $6 C, D$, accumulation of the ECD by glutamate treatment greatly diminished after inhibition of matrix metalloproteinases by the broad-spectrum inhibitor GM6001 $(10 \mu \mathrm{M})$, but not after BACE inhibition with $1 \mu \mathrm{M}$ BACE-IV $\left(p=0.0031 ; F_{(3,12)}=8.222\right.$; one-way ANOVA). Together with our previous work on NRG2 (Vullhorst et al., 2015), these data demonstrate that single-pass NRGs share important properties that govern their subcellular targeting and matrix metalloproteinase-dependent ectodomain shedding in response to NMDAR activation.

\section{NRG3 is a dual-pass transmembrane domain protein}

Unlike single-pass Ig-NRG1s and NRG2, dual-pass CRD-NRG1 accumulates on axons and axon terminals of peripheral and central neurons (Wolpowitz et al., 2000; Birchmeier and Nave, 2008). Whereas the membrane topology of NRG1 isoforms has been extensively studied, little is known about the membrane topology and subcellular targeting of NRG3, arguably the most broadly expressed NRG in the postnatal CNS (Zhang et al., 1997; Longart et al., 2004). NRG3 harbors neither CRD- nor Ig-like domains in its amino-terminal half (NTD); however, it contains a hydrophobic stretch of 23 amino acids between residues 69 and 


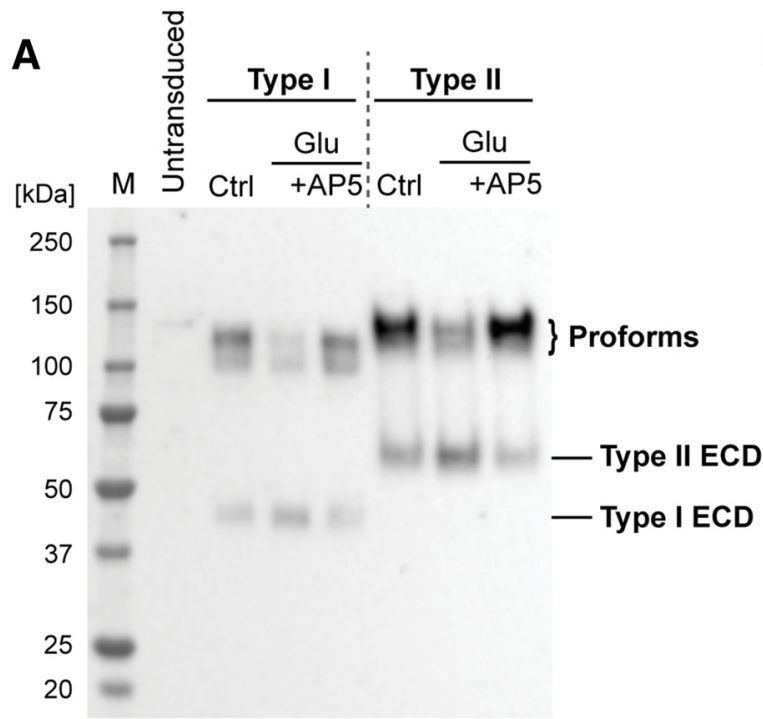

Antibody: V5 (anti-ECD)

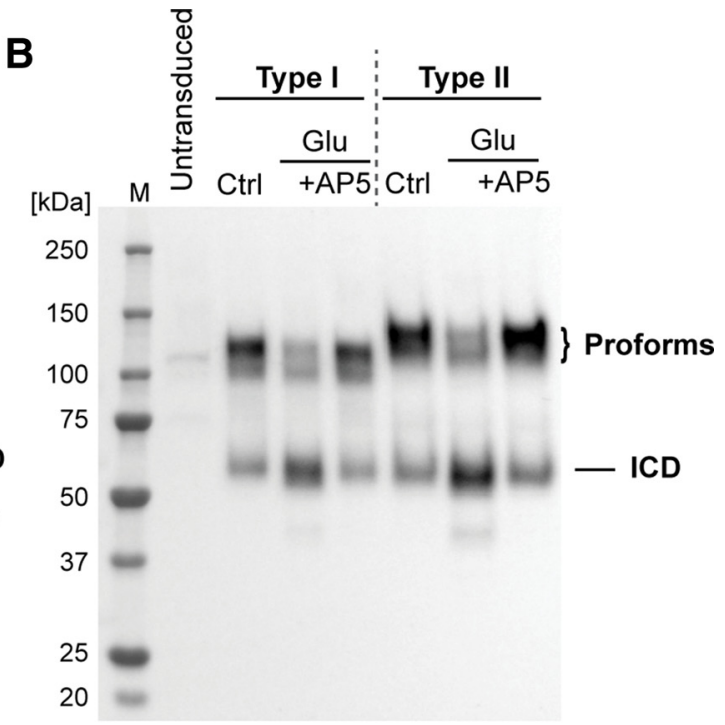

Antibody: SC-348 (anti-ICD)
C

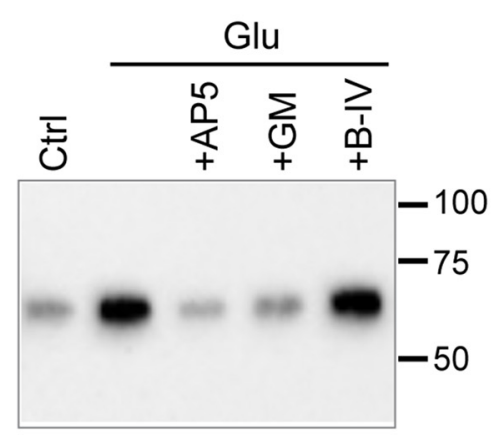

D

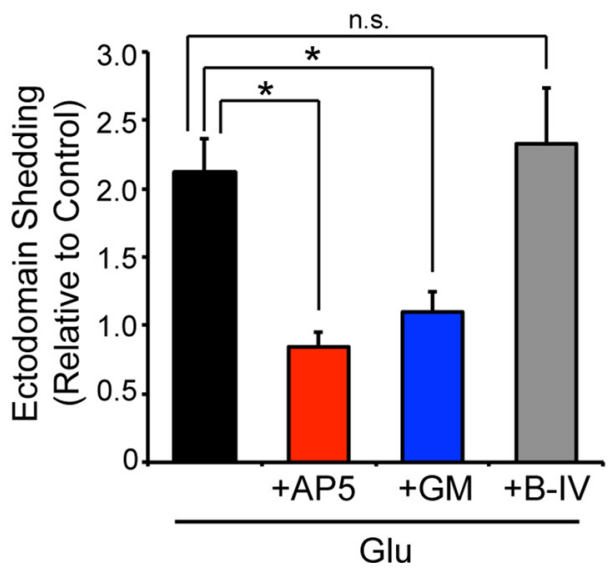

Figure 6. Type I and Type II NRG1 accumulate as unprocessed proteins and are shed by matrix metalloproteinases in response to NMDAR activation by glutamate. $A, B$, Western blot of whole-cell lysates from cultured hippocampal neurons transduced with AAVs harboring V5-tagged Type I or Type II NRG1, and incubated with (A) anti-V5 to detect their unprocessed proforms and ECD fragments, or (B) SC-348 to detect unprocessed proforms and the processed ICD fragment. Both ECD and ICD antibodies reveal that the bulk of single-pass NRGs in cell lysates is unprocessed at steady state (Ctrl), consistent with the overlap between ECD and ICD signals in ICC (Fig. 2E) and IFH (Figs. 4F-J, 5). Glutamate (Glu; $20 \mu \mathrm{m}$ for 20 min) promotes the generation of ECD and ICD fragments. This effect is blocked by AP5 $(+A P 5)$, indicating that processing is regulated in an NMDA receptor-dependent manner. $\mathbf{C}, \mathbf{D}$, Heparin pulldown of the Type II NRG1 ectodomain from medium conditioned by AAV-transduced hippocampal neurons, using anti-V5 for Western blotting. Ectodomain shedding by glutamate is sensitive to inhibition of NMDA receptors ( + AP5) and of metalloproteinases by GM6001 $(10 \mu \mathrm{M} ;+G M)$ but not of BACE by BACE-IV $(1 \mu \mathrm{M} ;+B-I V)$. D , Summary data were normalized to untreated controls (arbitrarily set to 1$)$ and represent the mean \pm SEM from four independent experiments. $p$ values were derived from multiple pairwise comparisons between Glu and Glu + inhibitor treatments: ${ }^{*} p<0.05$ (one-way ANOVA with Dunnett's post hoc test).

91. Analysis of the NRG3 protein sequence using a hidden Markov model for the prediction of transmembrane topology (TMHMM2.0 program) (Krogh et al., 2001) suggests that this area forms an $\alpha$-helical transmembrane stretch (Fig. 7A). We began to experimentally explore the transmembrane topology of NRG3 by transfecting HEK293 cells with a construct harboring the V5 epitope upstream of the EGF-like domain and the HA epitope upstream of this putative $\mathrm{TM}_{\mathrm{N}}$ (NRG3/HA-V5; Fig. 7B). The pattern and intensity of $\mathrm{V} 5$ immunoreactivity were comparable under permeabilizing and nonpermeabilizing conditions, indicating that NRG3/HA-V5 was efficiently targeted to the plasma membrane. By contrast, HA immunoreactivity was only detectable under permeabilizing conditions, consistent with the prediction of a second transmembrane domain near the amino terminus that would render the location of the HA epitope intracellular (Fig. 7B). To test whether the amino-terminal sequence including the putative $\mathrm{TM}_{\mathrm{N}}$ alone is sufficient to target the protein to the plasma membrane, we generated NRG3/NTD-GFP, a construct in which the entire NRG3 sequence downstream of the $\mathrm{TM}_{\mathrm{N}}$ was replaced by GFP. Indeed, surface labeling of transfected HEK293 cells with anti-GFP under nonpermeabilizing conditions revealed strong cell-associated immunoreactivity (Fig. 7C). Together, these data support the notion that NRG3 is a dual-pass transmembrane protein, and that NRG3 and CRD-NRG1 share a common membrane topology.

\section{NRG3 accumulates on axonal varicosities}

Next, we sought to investigate the subcellular distribution of NRG3 in transfected hippocampal neurons. Similar to the reported distribution of CRD-NRG1, and in striking contrast to single-pass Ig-NRGs, NRG3/V5 formed discrete small puncta on 

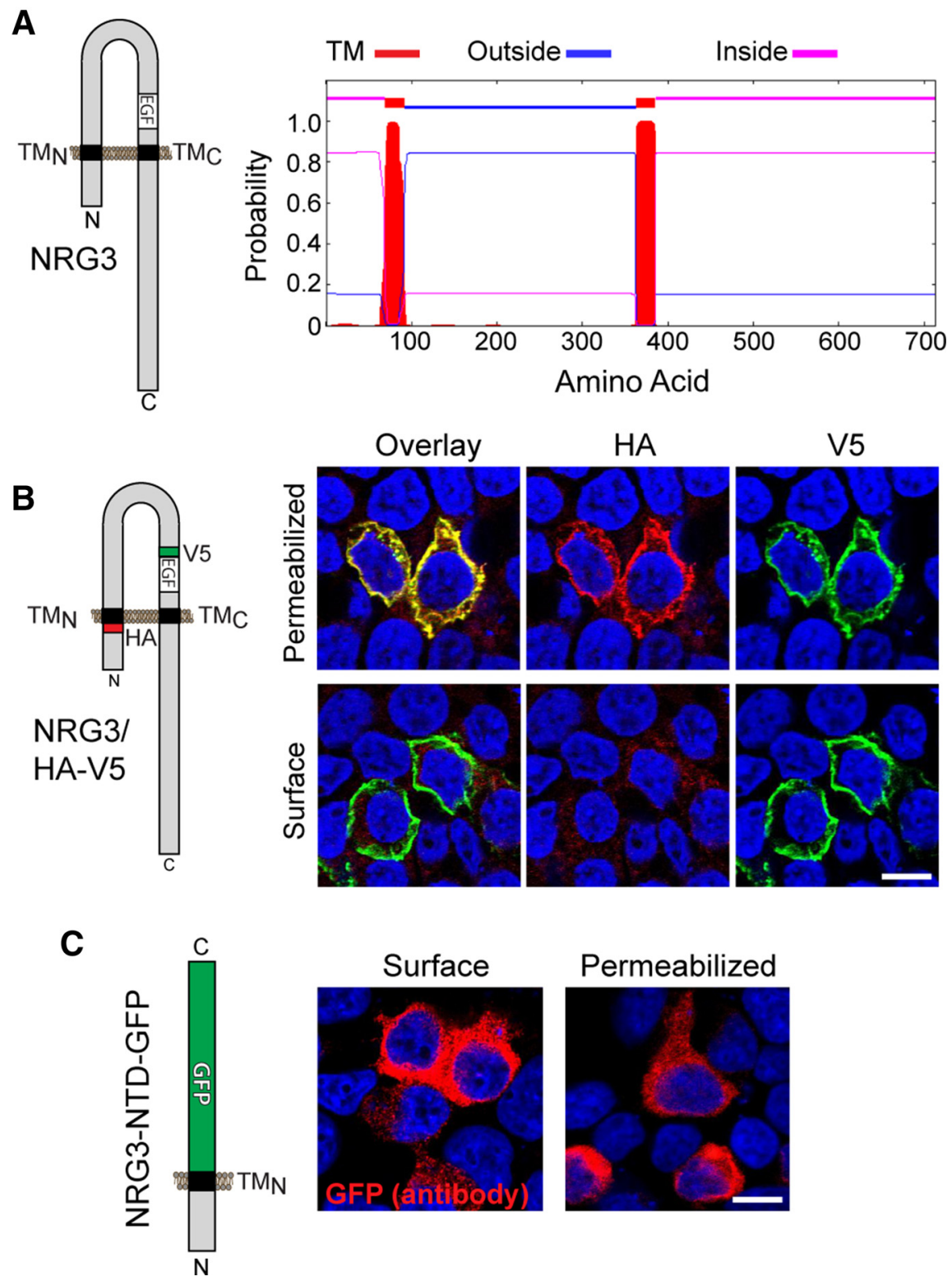

Figure 7. NRG3 is a dual-pass transmembrane domain protein. $\boldsymbol{A}$, The presence of an additional transmembrane domain $\left(\mathrm{TM}_{\mathrm{N}}\right)$ in mouse NRG3 (accession number:NP_032760.1) between residues 69 and 91 is predicted by a hidden Markov model (TMHMM2.0 program) (Krogh et al., 2001). As in CRD-NRG1, sequences upstream of $\mathrm{TM}_{N}$ and downstream of $\mathrm{TM}_{C}$ are therefore predicted to be intracellular, whereas sequences between $\mathrm{TM}_{\mathrm{N}}$ and $\mathrm{TM}_{\mathrm{C}}$, including the EGF-like domain, are extracellular. $\boldsymbol{B}$, Analysis of NRG3 membrane topology in transfected HEK293 cells. Left, The NRG3 construct was V5-tagged near the EGF-like domain and HA-tagged immediately upstream of the $\mathrm{TM}_{\mathrm{N}}$. Right, Under permeabilizing conditions, both anti-V5 and anti-HA antibodies bind NRG3/HAV5. Under nonpermeabilizing conditions (i.e., surface labeling), only V5 immunoreactivity is observed. C, HEK293 cells transfected with NRG3-NTD-GFP, comprised of NRG3 sequences between the N terminus and the $\mathrm{TM}_{\mathrm{N}}$ fused to GFP (left), are labeled with anti-GFP under both nonpermeabilizing (Surface) and permeabilizing conditions, consistent with the notion that the $\mathrm{N}$ terminus harbors a transmembrane domain that tethers GFP to the plasma membrane. All NRG3 constructs were in PDESTDV3.B, C, Confocal images are from a single plane. Scale bars, $10 \mu \mathrm{m}$.

varicosities of long processes (Fig. 8A). To determine whether these processes correspond to axons, hippocampal neurons were cotransfected with NRG3/V5, GFP-SNPH- $\triangle$ MTB, a marker that associates with axonal mitochondria (Kang et al., 2008), and with mCherry to uniformly fill all neuronal processes. As shown in Figure $8 B$, NRG3/V5 puncta were frequently located on GFP-SNPH$\Delta$ MTB-positive axonal processes; a quantitative analysis revealed that $88 \pm 1.4 \%$ (SEM) of NRG3/V5-immunoreactive puncta were on axons $(n=10$ ROIs from three independent experiments). Furthermore, consistent with the selective NRG3 ac- cumulation in axons, neurons cotransfected with NRG3/V5 and HA-tagged CRDNRG1, previously shown to be in axons using immunological and functional approaches (Wolpowitz et al., 2000; Hancock et al., 2008), showed extensive overlap between anti-V5 and anti-HA signals at varicosities (Fig. 8C).

Next, we investigated whether these varicosities correspond to bona fide synaptic contacts by using well-established presynaptic and postsynaptic markers, including PSD-95 for glutamatergic synapses where ErbB4 clusters at postsynaptic densities (Garcia et al., 2000; Huang et al., 2000). To this end, we transduced cultured hippocampal neurons with AAVs expressing CRD-NRG1/V5 or NRG3/V5 under the control of the Synapsin I promoter, and triple-labeled neurons at DIV 14, DIV 21, and DIV 28 with antibodies against V5, the general presynaptic marker bassoon, and PSD-95 (Fig. 8D,E). We found that V5-immunoreactive puncta for NRG3 and CRD-NRG1 accumulate at both synaptic and nonsynaptic sites (Fig. $8 D, E$, top). The fraction of NRG3 puncta that colocalized with bassoon increased significantly from $0.11 \pm 0.014$ (SEM) at DIV 14 to $0.37 \pm 0.038$ at DIV $28(p<$ $0.0001 ; F_{(2,27)}=32.77$; one-way ANOVA). PSD-95 colocalization also significantly increased from $0.17 \pm 0.023$ at DIV 14 to $0.41 \pm 0.038$ at DIV $28(p<0.0001$; $\left.F_{(2,27)}=27.62\right)$. In that same time frame, the fraction of CRD-NRG1 puncta that colocalized with bassoon increased from $0.08 \pm 0.034$ to $0.4 \pm 0.03(p<0.0001$; $\left.F_{(2,27)}=29.81\right)$, and from $0.16 \pm 0.017$ to $0.51 \pm 0.054$ for colocalization with PSD-95 $\left(p<0.0001 ; F_{(2,27)}=38.85\right)$. Furthermore, the total number of $V 5$ puncta also increased for both NRG3 and CRD-NRG1 (2.2-fold for CRD-NRG1 and 1.6-fold for NRG3 at DIV 21, and 4.8-fold for CRDNRG1 and 2.9-fold for NRG3 at DIV 28, relative to DIV 14). These data indicate that a subset of CRD-NRG1- and NRG3-containing axonal varicosities constitute bona fide excitatory presynaptic sites, as defined by bassoon and PSD95 colocalization, whereas other varicosities might represent sites destined for future synapse formation.

The NRG EGF-like domain is important for axonal clustering at sites of ErbB4 accumulation

ErbB4 protein in GABAergic interneurons is enriched at excitatory postsynaptic densities (Garcia et al., 2000; Huang et al., 2000). We therefore explored the possible colocalization between NRG3 puncta on axons and ErbB4 on GABAergic interneuron dendrites by double immunofluorescence cytochemistry of transfected hippocampal neurons. Indeed, we observed that NRG3/V5 puncta extensively colocalized in trans with ErbB4 
(Fig. 9A). Quantitative analyses revealed that a large fraction of NRG3 puncta colocalized with ErbB4 puncta at both DIV $10(0.85 \pm 0.02)$ and DIV 21 (0.86 \pm $0.03)$; in parallel experiments, a similar overlap was observed between CRDNRG1/V5 and ErbB4 (DIV 10: $0.86 \pm$ 0.02; DIV 21: $0.92 \pm 0.02$ ) (Fig. 9B). This high degree of overlap suggested that dual-pass NRGs accumulate on axons through juxtacrine interactions with ErbB4 receptors. To directly address this possibility, neurons were transfected at DIV 8 with GFP and NRG3/V5 or CRDNRG1/V5, and incubated for $2 \mathrm{~d}$ with soluble recombinant NRG1 EGF-like domain $(60 \mathrm{~nm})$. As shown in Figure 9C, GFP-positive neurites of both NRG3 and CRD-NRG1-transfected untreated neurons harbored numerous V5 puncta that colocalized with ErbB4. By contrast, no such puncta were observed in the presence of the EGF-like domain, indicating that the free EGF-like domain disrupted NRG puncta by competing for binding to ErbB4. Next, we cotransfected hippocampal neurons with a chimeric variant of NRG3/V5 in which its EGF-like domain was replaced by the corresponding domain of TGF- $\alpha$ (Fig. 9D), a member of the EGF superfamily previously shown to bind ErbB1 but not ErbB4 (Jones et al., 1999); CRD-NRG1/HA was cotransfected as an internal reference. Despite comparable expression levels in transfected HEK 293 cells and AAV-transduced cultured neurons (Fig. 9D), the chimeric TGF_NRG3/V5 protein failed to form axonal puncta, as demonstrated by the lack of V5 immunoreactivity at sites of CRD-NRG1/HA accumulation (Fig. 9E). Together, we conclude that axonal accumulation of NRG3 and CRDNRG1 is dependent upon stable juxtacrine interactions with ErbB4 at varicosities, and that some of these sites correspond to glutamatergic synapses.

\section{Axonal clusters of CRD-NRG1 and NRG3 are comprised of BACE- processed proteins}

Ig-NRGs cluster as unprocessed proforms at SSC-type neuronal ER-PM contact sites (Vullhorst et al., 2015; this study). To determine whether axonal clusters of CRD-NRG1 and NRG3 are comprised of either processed or unprocessed forms, we transfected hippocampal neurons with NRG3/V5 and CRD-NRG1/V5 constructs and simultaneously detected their ECDs with anti-V5 and their c-terminal ICDs with antibodies specific for NRG1 (SC-348) or NRG3 (1352). In stark contrast to singlepass NRGs (Figs. 2-5), these experiments revealed that V5 puncta lacked accompanying ICD signals, suggesting that both NRGs

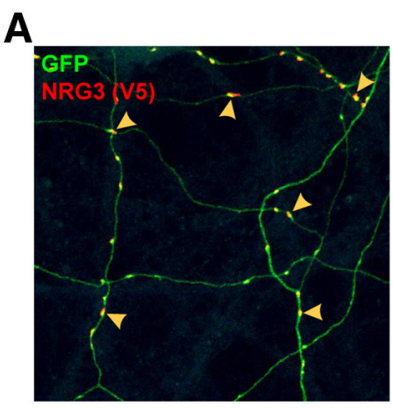

B

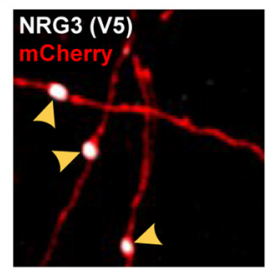

D
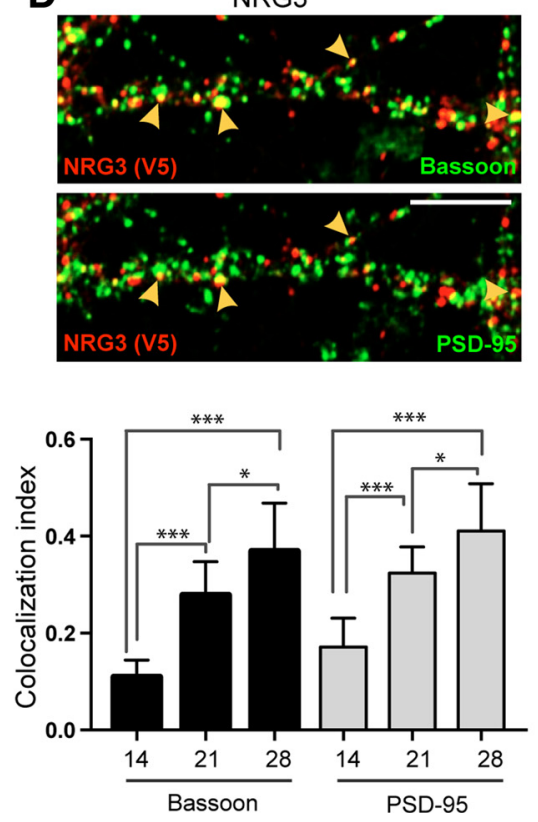

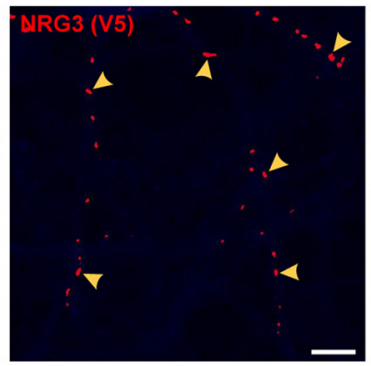

C
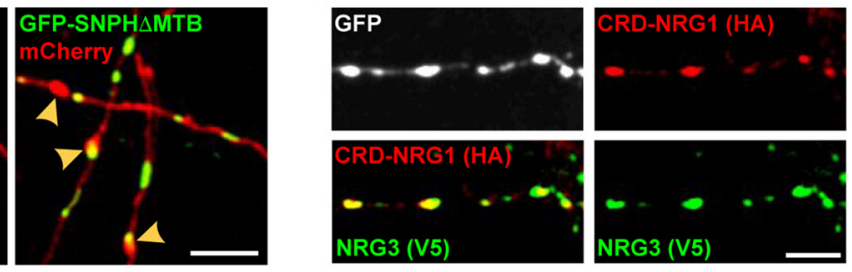

E
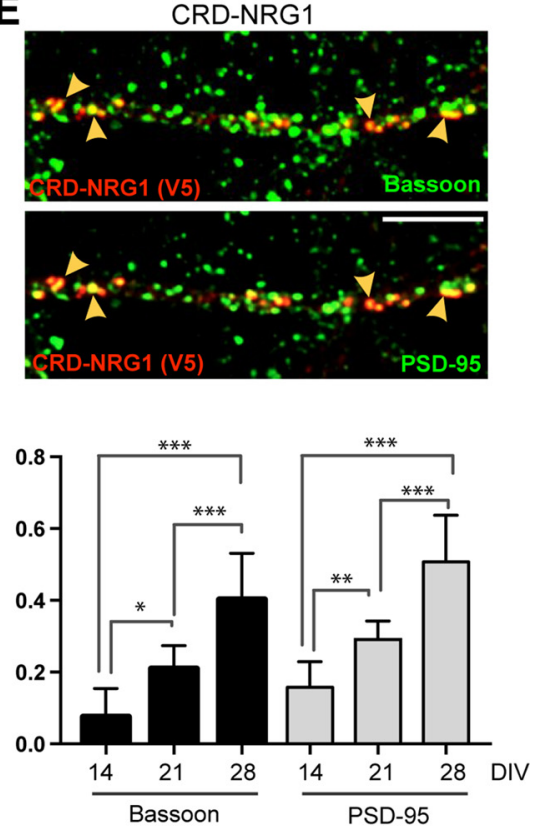
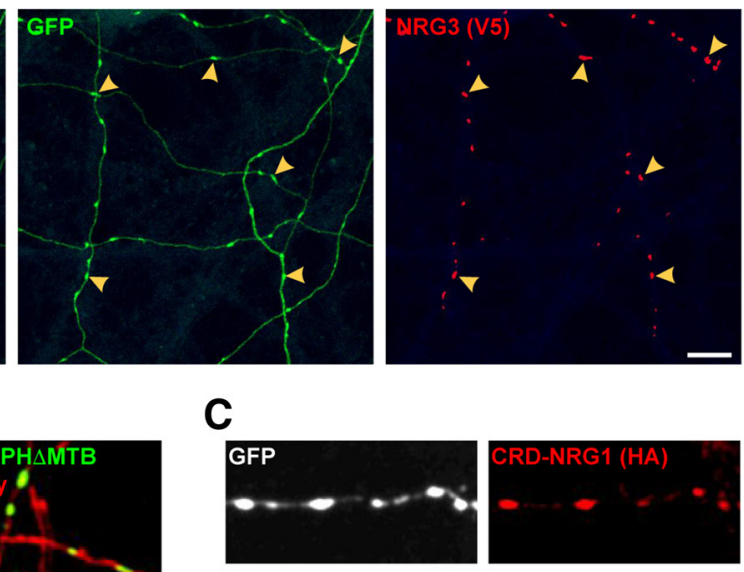

Figure 8. NRG3 accumulates on axonal varicosities, some of which are bona fide glutamatergic terminals. $\boldsymbol{A}$, Hippocampal neurons were cotransfected with NRG3/V5 in pDESTDV3 and GFP. The representative low-magnification image shows GFP-positive processes with V5 signal accumulating at varicosities (arrowheads). $\boldsymbol{B}$, Neurons were cotransfected with NRG3/V5, mCherry, and the axonal marker GFP-SNPH- $\Delta$ MTB. Left, The mCherry/V5 overlay image shows three NRG3 puncta on mCherry-positive processes (arrowheads). The presence of GFP-SNPH- $\triangle$ MTB signals in these processes in the corresponding mCherry/GFP-SNPH$\Delta$ MTB overlay image (right) reveals that these processes are axons. C, Neurons cotransfected with CRD-NRG1/HA and NRG3/V5 show extensively overlapping immunoreactivity for both tags at axonal varicosities. D, E, CRD-NRG1 and NRG3 accumulate at presynaptic terminals. Top, Middle, Hippocampal neurons were transfected with NRG3/V5 (D) or CRD-NRG1/V5 (E) and colabeled with antibodies against V5, Bassoon, and PSD-95. The representative DIV 21 images illustrate the partial overlap between V5, the presynaptic marker Bassoon (top), and the postsynaptic marker PSD-95 (middle). Arrowheads indicate examples of synaptic sites that are positive for V5, Bassoon, and PSD-95. Bottom, Corresponding quantitative colocalization data for NRG3/V5 and CRDNRG1/V5 derived from the analysis of V5 puncta at DIV 14, DIV 21, and DIV 28. For both NRG3 and CRD-NRG1, the fraction of V5 puncta colocalizing with synaptic markers significantly increases during in vitro development. Data are mean \pm SEM of the fraction of V5 puncta colocalizing with synaptic markers from a total of 27-40 ROls acquired in three independent experiments. $p$ values were derived from multiple comparisons within each group using one-way ANOVA with Tukey's post hoc test. ${ }^{*} p<0.05$. ${ }^{* *} p<$ 0.01. ${ }^{* * *} p<0.001$. Scale bars: $\boldsymbol{A}, 20 \mu \mathrm{m} ; \boldsymbol{B}, \boldsymbol{C}, 5 \mu \mathrm{m} ; \boldsymbol{D}, \boldsymbol{E}, 10 \mu \mathrm{m}$.

accumulate as processed proteins (Fig. 10A). To further support this conclusion, we analyzed the apparent molecular masses of V5-immunoreactive bands by Western blotting of whole-cell extracts prepared from AAV-transduced hippocampal neurons. As 
A
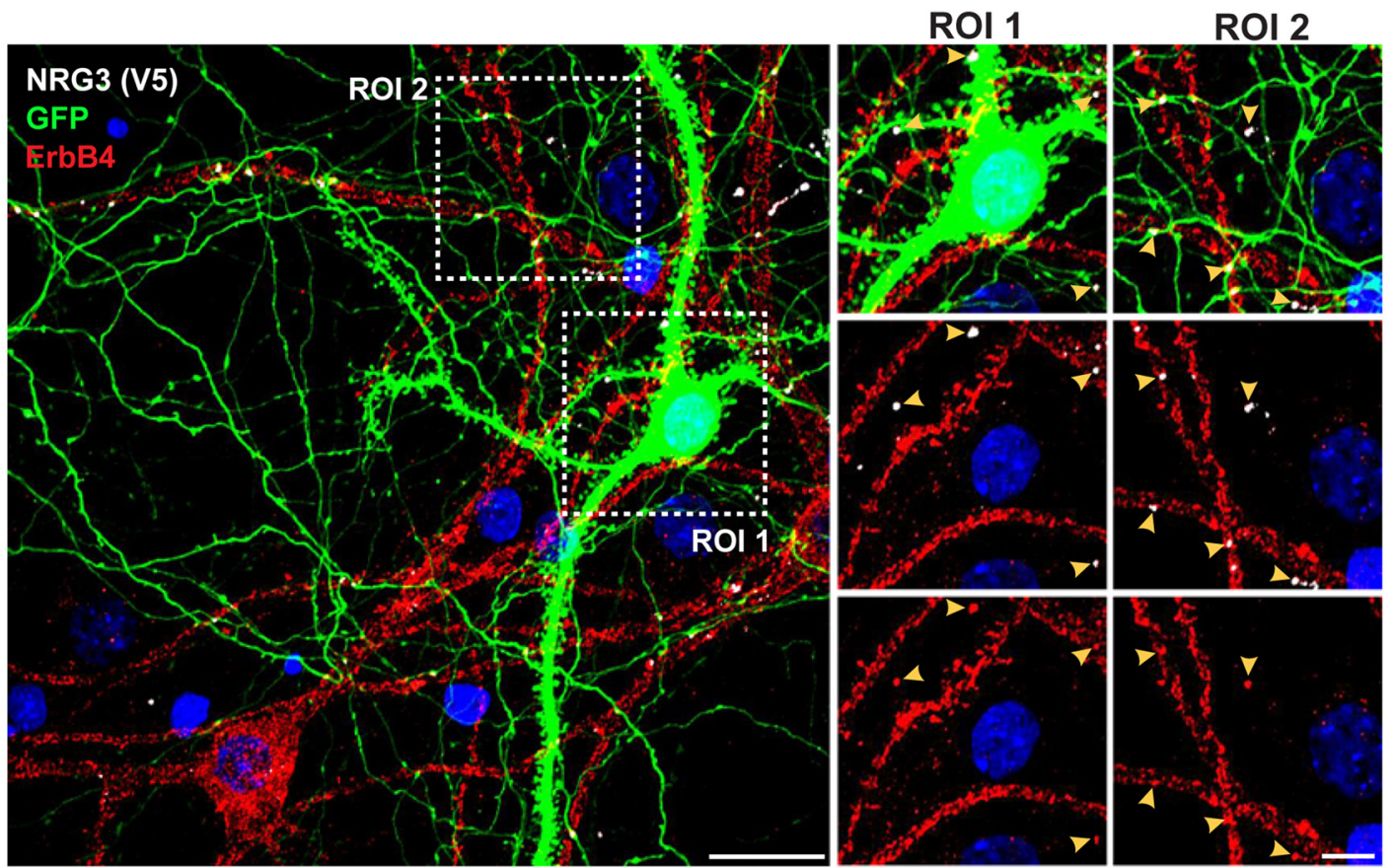

B

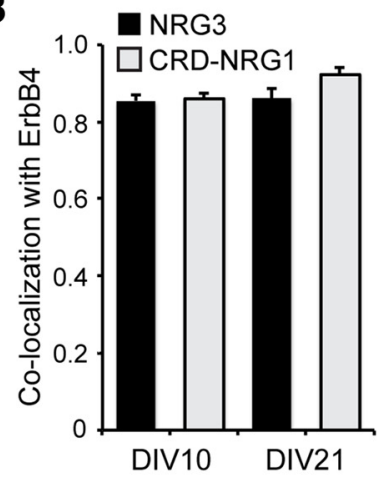

D

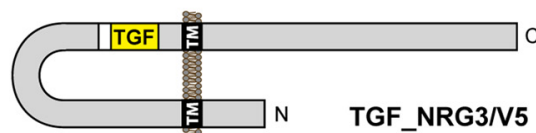

\section{NRG3/V5}

NRG3/V5

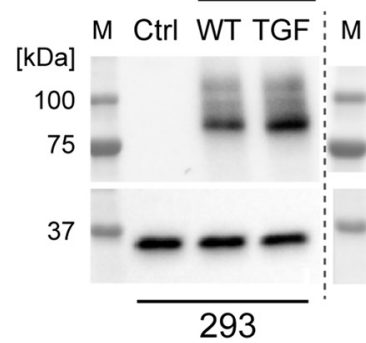

C

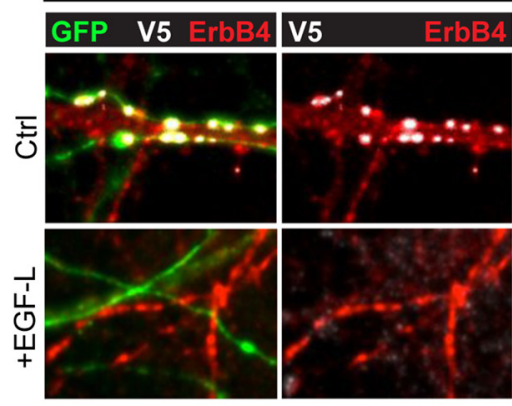

E
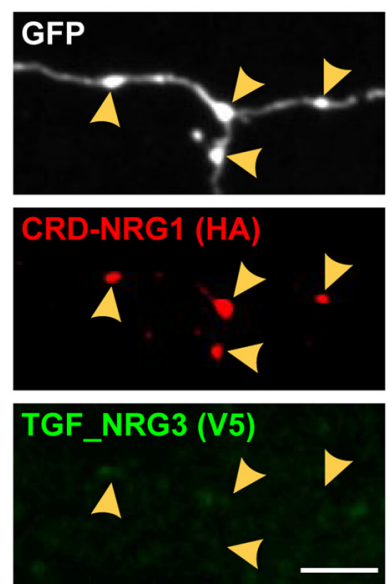

Figure 9. Axonal NRG3/CRD-NRG1 puncta are sites of juxtracrine interactions with ErbB4. $\boldsymbol{A}$, Hippocampal neurons were transfected with NGR3/V5 and GFP as detailed in Figure 8 and labeled with anti-V5 and anti-ErbB4 antibodies. The representative low-magnification image shows a GFP-positive and ErbB4-negative transfected neuron next to an ErbB4-positive untransfected neuron. The two magnified ROIs illustrate how the transfected neuron lacks V5 immunoreactivity on its cell body (ROI 1) but harbors numerous V5 puncta on processes that overlap with ErbB4 signals on the untransfected neuron (ROI 1 and ROI 2, arrowheads). B, Quantitative analysis of colocalization of V5-tagged NRG3 and (RD-NRG1 with endogenous ErbB4 in transfected hippocampal neurons at DIV 10 and DIV 21. Data are mean \pm SEM of 10 ROls each from three separate experiments. C, V5 puncta reflecting accumulation of NRG3 (left) or CRD-NRG1 (right) on GFP-positive processes from transfected DIV 10 neurons (top) are absent from cultures treated with the NRG1 EGF-like domain (bottom). D, Top, Schematic illustration of the chimeric TGF_NRG3/V5 construct. Bottom, Anti-V5 Western blots confirming comparable expression of wild-type NRG3/V5 (WT) and TGF_NRG3/V5 (TGF) in transfected HEK 293 cells and in AAV-transduced cultured neurons. Blots were reprobed with anti-GAPDH to confirm equal loading. Untransfected/untransduced controls (Ctrl) were included to confirm specificity of the NRG3 bands. $\boldsymbol{E}$, Axonal process from a neuron cotransfected with TGF_NRG3/V5 and CRD-NRG1/HA (included as internal reference). Unlike normal NRG3, which colocalizes with CRD-NRG1 (Fig. 8C), TGF_NRG3/V5 is absent from axonal varicosities that harbor CRD-NRG1/HA puncta. Scale bars: $A$, Overview image, $20 \mu \mathrm{m} ; A$, Magnified ROls, $10 \mu \mathrm{m} ; \boldsymbol{C}, \boldsymbol{E}, 5 \mu \mathrm{m}$. 
A
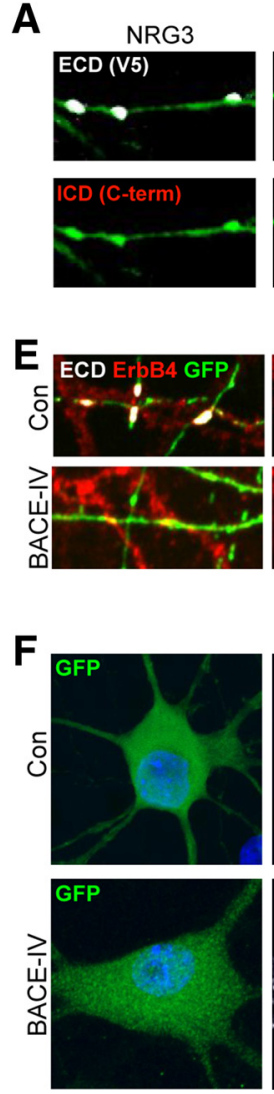

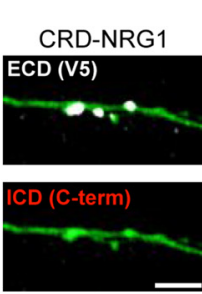

NRG3
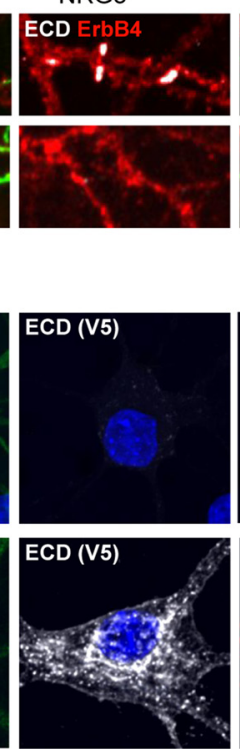
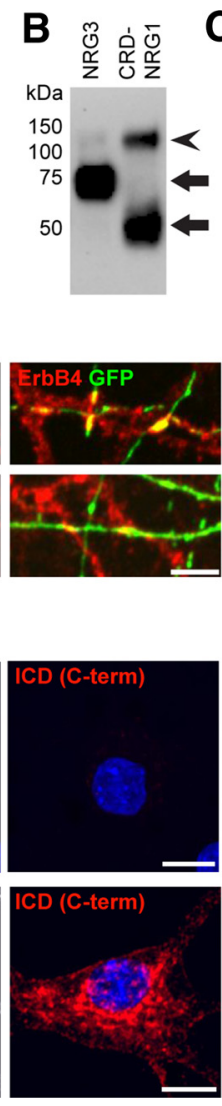

C
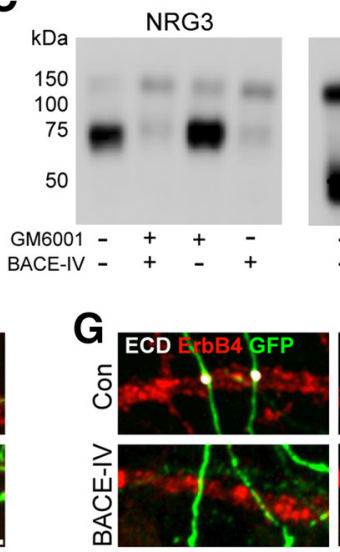

H

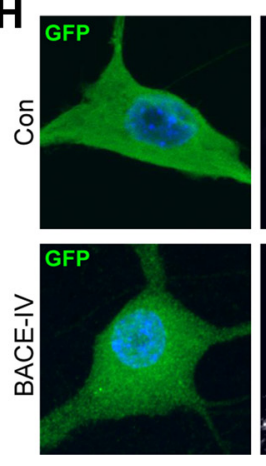

CRD-NRG1

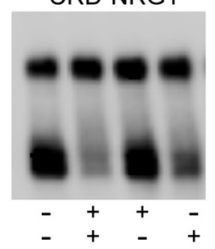

CRD-NRG1

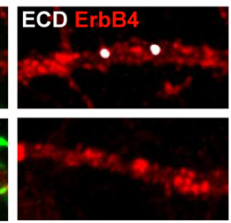

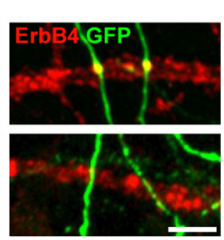

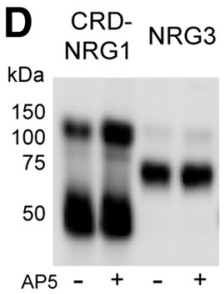

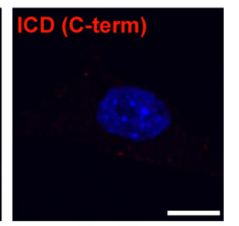
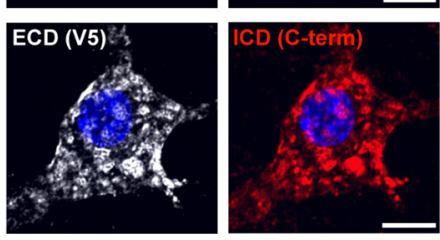

Figure 10. BACE inhibition prevents axonal accumulation of NRG3 and CRD-NRG1. $A$, Hippocampal neurons were cotransfected with GFP and NRG3/V5 or CRD-NRG1 as described in Figure 8, and labeled with anti-ECD (V5) and antibodies 1352 (NRG3) or SC-348 (NRG1) against their respective carboxyl-terminal ICDs. Representative images show processes of transfected (GFP-positive) neurons harboring punctate V5 signals (top) but lacking corresponding ICD signals (bottom), indicative of the accumulation of the processed rather than the unprocessed proteins. $\boldsymbol{B}-\boldsymbol{D}$, Anti-V5 Western blots of whole-cell lysates from neurons transduced with AAVs harboring NRG3/V5 or CRD-NRG1. B, Processed proteins (arrows) migrate at $\sim 70$ kDa (NRG3) and 50 kDa (CRD-NRG1) apparent molecular mass, whereas their corresponding unprocessed proforms (barely detectable for NRG3) migrate at $\sim 130-140 \mathrm{kDa}$ apparent molecular mass (arrowhead). C, Chronic (4 day) BACE inhibition with BACE-IV $(1 \mu \mathrm{M})$, but not of matrix metalloproteinases with GM6001 (10 $\mu \mathrm{m})$, blocks processing of NRG3 and CRD-NRG1 in transduced neurons. $D$, NMDA receptor blockade by AP5 (100 $\mu \mathrm{m}$ for $24 \mathrm{~h}$ ) does not inhibit processing of dual-pass NRGs. $\boldsymbol{E}-\boldsymbol{H}$, BACE inhibition blocks axonal accumulation of NRG3 and CRD-NRG1 and causes retention of their unprocessed proforms in the cell body. Hippocampal neurons were cotransfected with GFP and NRG3/N5 $(\boldsymbol{E}, \boldsymbol{F})$ or with GFP and CRD-NRG1/V5 $(\boldsymbol{G}, \boldsymbol{H})$, and treated for $4 \mathrm{~d}$ with $1 \mu \mathrm{MM}$ BACE-IV. Untreated neurons were included as controls (Con). Neurons were labeled with antibodies against the ECD (V5) and ErbB4 to analyze NRG accumulation on axonal processes $(\boldsymbol{E}, \boldsymbol{G})$, or with anti-V5 and antibodies against the respective carboxyl-terminal domains of NRG3 $(\boldsymbol{F})$ or NRG1 $(\boldsymbol{H})$ to analyze cell body accumulation observed in a subset of transfected neurons $(\boldsymbol{F}, \boldsymbol{H})$. Scale bars: $\boldsymbol{A}, \boldsymbol{E}, \boldsymbol{G}, 5 \mu \mathrm{m} ; \boldsymbol{F}, \boldsymbol{H}, 10 \mu \mathrm{m}$.

shown in Figure 10B, the major NRG3 and CRD-NRG1 bands migrated at $\sim 70 \mathrm{kDa}$ and $\sim 50 \mathrm{kDa}$ apparent molecular mass, respectively, indicating that these bands correspond to their processed amino-terminal halves extending up to, but excluding, the downstream transmembrane domain $\left(\mathrm{TM}_{\mathrm{C}}\right)$.

Both BACE and the ADAM10/17 members of the family of extracellular metalloproteinases have been implicated in CRD-NRG1 processing in heterologous cell lines (Fleck et al., 2012). Western blot analysis revealed that chronic treatment $(4 \mathrm{~d})$ of AAV-transduced hippocampal neuron cultures with the BACE inhibitor BACE-IV (1 $\mu \mathrm{M}$ ) virtually eliminated NRG3 processing and greatly reduced processing of CRD-NRG1 (Fig. 10C), consistent with a high degree of homology between NRG3 and CRD-NRG1 over a 10 amino acid stretch encompassing the BACE cleavage site (Fig. 11A). By contrast, blockade of metalloproteinases with GM6001 $(10 \mu \mathrm{M})$ did not affect processing of either NRG3 or CRD-NRG1, indicating that BACE plays a dominant role in the cleavage of dual-pass NRGs in neurons. We also asked whether NMDARs are involved in the processing of NRG3 and CRD-NRG1, as demonstrated for Type II NRG1 (Fig. 6) and NRG2 (Vullhorst et al., 2015). However, inhibition of NMDARs by AP5 $(100 \mu \mathrm{M})$ for $24 \mathrm{~h}$ did not affect processing of either CRDNRG1 or NRG3 (Fig. 10D). Together, these findings indicate that, in stark contrast to single-pass Ig-NRGs, both dual-pass NRGs are processed by BACE independently of NMDAR activity.

\section{Processing by BACE is required for axonal clustering of CRD-NRG1 and NRG3}

We sought to explore a possible causal relationship between BACE-dependent NRG3/CRD-NRG1 processing and axonal clustering. Hippocampal neurons were transfected with GFP and NRG3/V5 or CRD-NRG1/V5, and treated for $4 \mathrm{~d}$ with $1 \mu \mathrm{M}$ BACE-IV as described above. To analyze axonal processes, one set of neurons was colabeled with anti-ECD (V5) and anti-ErbB4 antibodies. To analyze cell bodies, another set was colabeled with anti-ECD (V5) and anti-ICD (NRG1: SC-348; NRG3: 1352) antibodies. Unlike untreated controls, neurons treated with BACE-IV lacked V5 puncta at sites where axons of transfected neurons intersected dendrites of ErbB4-positive neurons (Fig. $10 E, G)$. Furthermore, BACE inhibition caused cell body accumulation of unprocessed NRG3 and CRD-NRG1 proforms (immunoreactive with both ECD and ICD antibodies) in some transfected neurons (Fig. 10F,H). To exclude possible indirect effects of chronic BACE inhibition on NRG trafficking, we used an orthogonal approach by mutating NRG3 and CRD-NRG1 in the area upstream of their respective $\mathrm{TM}_{\mathrm{C}}$ transmembrane domains to render them resistant to BACE cleavage (Fig. 11A). Functionality of these constructs was verified by Western blotting of whole-cell lysates made from hippocampal neurons transduced with AAVs harboring normal and cleavage-resistant (cr) 
A

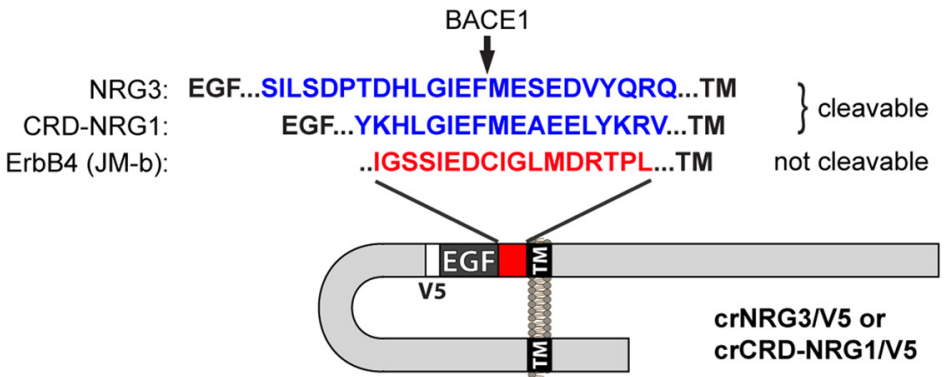

C
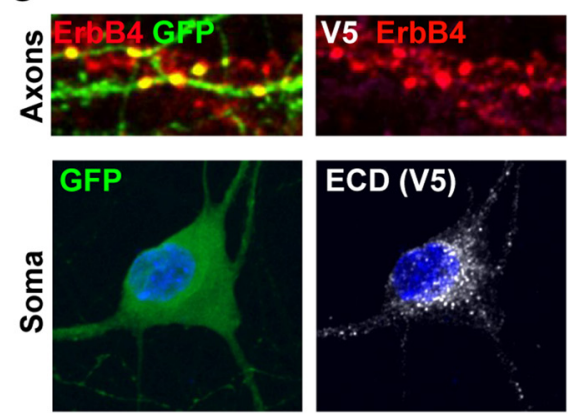

E

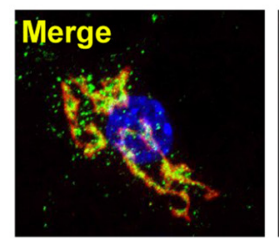

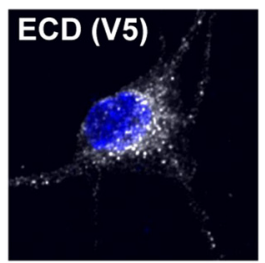

crNRG3

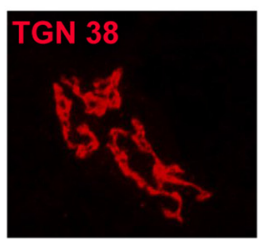

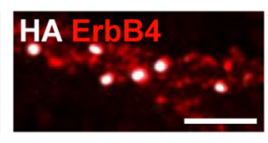
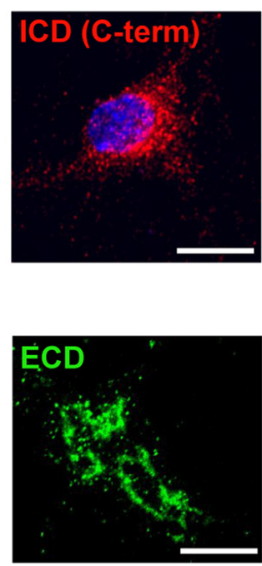

D
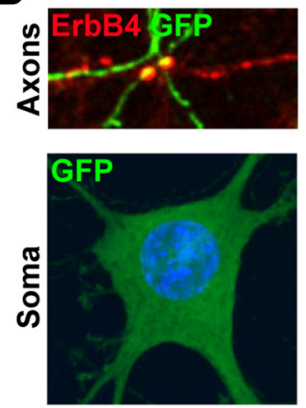

F

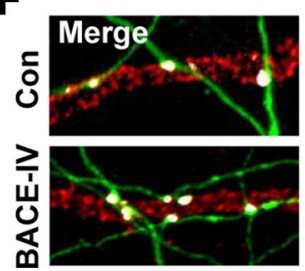

B

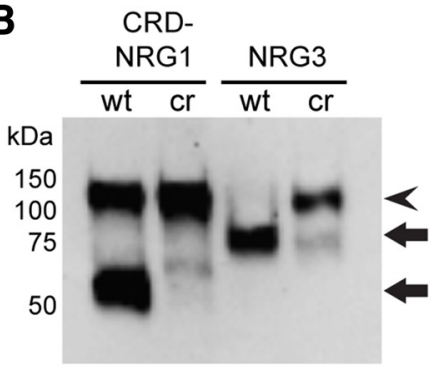

CrCRD-NRG1
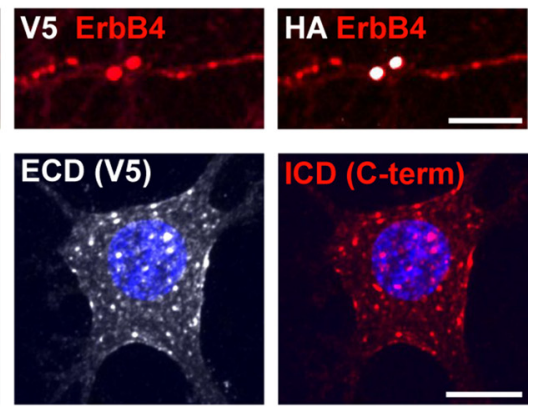

NRG3(Q360*)
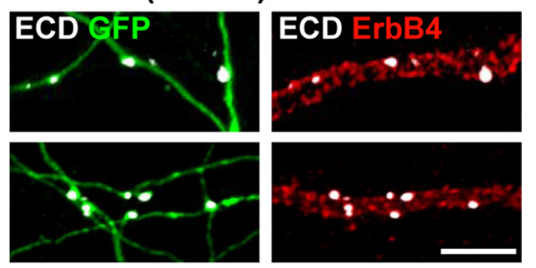

Figure 11. Axonal accumulation is impaired in cleavage-resistant variants of NRG3 and CRD-NRG1. A, Schematic illustration of the strategy to render dual-pass NRGs resistant to processing near the $\mathrm{TM}_{\mathrm{c}}$. Briefly, the area between the EGF-like and TM domains of NRG3 and CRD-NRG1 was replaced by the shedding-resistant juxtamembrane region of the JM-b isoform of ErbB4 (Elenius et al., 1997). B, Western blot analysis of whole-cell lysates from hippocampal neurons transduced with AAVs harboring cleavable (wt) or cleavage-resistant (cr) variants of CRD-NRG1/V5 and NRG3/V5. Arrowhead indicates bands representing uncleaved proforms. Arrows indicate processed proteins. $C, D$, Lack of axonal accumulation of cleavage-resistant NRG variants in neurons transfected with crNRG3/V5 ( $C$ or crCRD1-NRG1 ( $\boldsymbol{D}$ ) along with GFP and wtCRD-NRG1/HA (included as internal reference). Top, Neurons were triple-labeled with anti-ErbB4, anti-HA to reveal sites of axonal CRD-NRG1 accumulation, and anti-V5 to detect crNRG variants. GFP-positive axonal processes forming varicosities across from ErbB4 puncta (left) harbor wtCRD-NRG1 puncta (right) but lack corresponding signals for crNRG3 or crCRD-NRG1 (middle). Bottom, In parallel experiments, transfected neurons were labeled with antibodies against the ECDs (V5) and the carboxyl-terminal ICDs of crNRG3 or CRD-NRG1, as described in Figure 10. Representative images of transfected neuron cell bodies (left) show accumulation of crNRGs with both ECD (middle) and ICD (right) antibodies. $\boldsymbol{E}$, Representative confocal image of a crNRG3/V5-expressing hippocampal neuron labeled with anti-V5 and an antibody against the trans-Golgi marker protein TGN-38. $F$, Neurons were transfected with GFP and V5-tagged NRG3 $\left(Q 360^{*}\right)$ lacking the $\mathrm{TM}_{C}$ and downstream sequences. Representative confocal images of GFP-positive processes from transfected neurons labeled for V5 and ErbB4 showing NRG3(Q360*)-puncta under untreated control conditions (top) and after BACE-IV treatment (bottom). Scale bars: C, Top, D, Top, $5 \mu \mathrm{m} ; \boldsymbol{C}$, Bottom, $\boldsymbol{D}$, Bottom, $\boldsymbol{E}, \boldsymbol{F}, 10 \mu \mathrm{m}$.

versions of NRG3 and CRD-NRG1 (Fig. 11B). Next, hippocampal neurons were cotransfected with GFP, wild-type CRDNRG1/HA, and either crCRD-NRG1/V5 or crNRG3/V5, and immunolabeled with antibodies against HA, V5, and ErbB4. While wild-type CRD-NRG1 colocalized in trans with ErbB4 on dendrites of untransfected neurons, puncta comprised of crCRD-NRG1 and crNRG3 were notably absent from axons (Fig. $11 C, D)$. Instead, crNRG3 and crCRD-NRG1 consistently accumulated in cell bodies. Interestingly, we noticed that, whereas crCRD-NRG1 was broadly distributed throughout the entire cell body, crNRG3 immunoreactivity was mostly confined to the Golgi apparatus, as evidenced by colabeling with an antibody against the Golgi marker protein TGN38 (Fig. 11E). Conversely, a truncated variant of NRG3 with a stop codon inserted immediately upstream of the $\mathrm{TM}_{\mathrm{C}}\left(\mathrm{NRG} 3\left(\mathrm{Q} 360^{*}\right)\right)$, which mimics its processed form and is structurally similar to the naturally occurring NRG1 SMDF isoform that is transcribed from the Type III promoter (Ho et al., 1995), formed axonal puncta regardless of BACE inhibition (Fig. 11F). Collectively, these findings strongly support the notion that BACE-dependent processing of dual- pass NRGs is a prerequisite for their axonal accumulation through juxtacrine interactions with ErbB4, and reveal a previously unknown functional relationship between proteolytic processing and subcellular targeting of NRGs in neurons.

\section{Discussion}

The main findings of this study, based on evidence from cultured hippocampal neurons, are as follows: (1) Like CRD-NRG1, NRG3 is a dual-pass transmembrane protein. (2) Single- and dual-pass NRGs accumulate in distinct subcellular domains. (3) This differential distribution reflects accumulation of unprocessed single-pass NRGs at SSC-type ER-PM contact sites and accumulation of processed dual-pass NRGs on axons as a result of juxtracrine receptor interactions. (4) NMDA receptor activity promotes processing of single-pass but not dual-pass NRGs. (5) In neurons, single-pass NRGs are processed by matrix metalloproteinases, whereas dual-pass NRGs are processed by BACE. Together, these findings (summarized schematically in Fig. 12) establish a new conceptual framework for NRG isoform diversity that is based on their cell biological properties. 
Activity-dependent ectodomain shedding of single-pass NRGs from cell body ER-PM contact sites

The prevailing notion until now has been that axonal targeting represents a common feature of most neuronal NRGs. This paradigm is based partly on early immunohistological analyses of NDF/ARIA (synonymous with Type I NRG1) expression at the neuromuscular junction using antibodies directed against the EGF-like domain that is common to all NRG1 isoforms (Chu et al., 1995; Jo et al., 1995; Moscoso et al., 1995). These analyses were performed before the existence of the Type III promoter, which generates CRDNRG1 and SMDF isoforms, was known and the functional importance of these NRG isoforms for the development and maintenance of sensory neurons and motorneurons recognized (Ho et al., 1995; Wolpowitz et al., 2000). Together with previous studies from our laboratory and by others (Gallart-Palau et al., 2014; Vullhorst et al., 2015), it is now becoming evident that an important aspect of NRG isoform diversity, at least in central neurons, is to target NRGs to distinct subcellular compartments, in addition to providing distinct spatiotemporal gene expression regulation during development and in the adult (Fig. 12A) (Buonanno and Fischbach, 2001; Falls, 2003; Birchmeier and Nave, 2008). This finding has important implications for the ways in which single-pass NRGs are thought to regulate neuronal functions. At the most fundamental level, they can be thought of as providing a local source of signal that acts in paracrine mode on nearby neurons or glia, or in autocrine mode as shown for NRG2 in ErbB4-positive GABAergic interneurons (Vullhorst et al., 2015). Interestingly, Type II NRG1-expressing GABAergic neurons in the RTN (this study) also coexpress ErbB4 (Gerecke et al., 2001) and therefore might also engage in autocrine signaling. The Ig-like domain, although not required for targeting per se, likely serves to retain the processed ectodomain near the source, thereby reinforcing the spatially restricted nature of this signal. Although not directly tested here, we predict that other Ig-NRG1s (Types IV-VI) share the properties of the single-pass NRGs tested in this study (Steinthorsdottir et al., 2004; Tan et al., 2007). It should also be noted that release of Ig-NRG1s from peripheral axons during early postnatal development was reported to support Schwann cell survival and differentiation (Esper and Loeb, 2004; Ma et al., 2011), suggesting that subcellular NRG isoform distribution might be differentially regulated during development and/or in different neuron types.

Previous studies implicated ADAMs (a disintegrin and metalloproteinase), in particular ADAM17/TACE, in NRG1 processing (Horiuchi et al., 2005; La Marca et al., 2011; Fleck et al., 2013). Our findings showing that NMDAR-dependent ectodomain shedding of single-pass NRGs is sensitive to metalloproteinase inhibition are consistent with those reports. How NMDAR activity promotes NRG ectodomain shedding by ADAMs is currently not known, although available evidence suggests that calcium influx via NMDARs could either directly regulate ADAMs (Nagano et al., 2004), possibly via PKC-dependent pathways (Loeb et al., 1998), or indirectly promote shedding by disrupting the integrity of ER-PM contacts (Fox et al., 2015).

Functional implications of NMDAR-dependent ectodomain shedding of single-pass NRGs from neuronal cell bodies One plausible physiological effect of local autocrine signaling via single-pass Ig-NRGs is NMDAR-dependent regulation of intrinsic excitability in ErbB4-expressing GABAergic interneurons, a notion supported by earlier data from our group showing that soluble recombinant NRG1-EGFL acutely increases action potential threshold of cultured ErbB4-positive hippocampal interneurons by downregulating voltage-gated sodium channels (Janssen et al., 2012). Together with other reports showing that 
activation of (extrasynaptic) NMDARs shifts the voltage dependency of Kv2.1 channel function to more negative membrane potentials (Murakoshi et al., 1997; Misonou et al., 2004; Mulholland et al., 2008), it is conceivable that NMDAR-mediated NRG ectodomain shedding and augmentation of Kv2.1 channel function work in concert to downregulate intrinsic excitability via opposing effects on voltage-gated sodium and potassium channels, and could serve as an adaptive response to potentially harmful increases in ambient glutamate levels. Moreover, bidirectional signaling between NRG2-ErbB4 and NMDARs in GABAergic interneurons modulate NMDAR-mediated currents (Vullhorst et al., 2015) and could therefore regulate excitatory/inhibitory balance in cortical microcircuits. This functional link could also be pertinent to the recently identified role of ErbB4 signaling in $\mathrm{PV}^{+}$ GABAergic interneurons for critical period plasticity in the visual cortex (Gu et al., 2016; Sun et al., 2016), and might constitute a point of convergence for separate findings on the roles of NMDARs, the extracellular matrix (perineuronal nets), and ErbB4 in $\mathrm{PV}^{+}$GABAergic interneurons (Pizzorusso et al., 2002; Morishita et al., 2015; Kaplan et al., 2016).

\section{Dual-pass NRGs accumulate on axons following processing by BACE}

As illustrated in Figure 12B, our results indicate that processing of dual-pass NRGs follows a different route than that of single-pass Ig-NRGs. Intracellular cleavage by BACE, as revealed by the accumulation of unprocessed or cleavage-resistant NRG in the Golgi and other vesicular compartments, is consistent with studies showing that BACE preferentially cycles between the transGolgi network and endosomes (Vassar et al., 1999; Yan et al., 2001), and that the $\mathrm{pH}$ in these compartments provide conducive conditions for BACE enzymatic activity (Yamashiro and Maxfield, 1984; Demaurex et al., 1998; Fukumoto et al., 2002). Furthermore, it is in agreement with a recent study in HEK 293 cells showing that CRD-NRG1 processing by BACE does not require surface delivery or endocytosis (Ben Halima et al., 2016). However, that and other studies in heterologous cell lines were, by design, not able to capture the requirement of BACE-mediated processing for axonal clustering of CRD-NRG1 and NRG3 in neurons. This striking result suggests that BACE processing enables juxtacrine interactions with ErbB receptor. In further support of the notion that the NTD of dual-pass NRGs alone is sufficient for axonal clustering, we demonstrated that a NRG3 variant with a stop codon immediately upstream of the $\mathrm{TM}_{\mathrm{C}}$ $\left(\mathrm{NRG} 3\left(\mathrm{Q} 360^{*}\right)\right)$, that is structurally similar to the naturally occurring NRG1 isoform SMDF (Ho et al., 1995), accumulates on axonal varicosities regardless of BACE activity. Whether this transport is directional or whether preferential axonal accumulation is merely the result of selective retention of processed CRD-NRG1/NRG3 by ErbB4, as suggested by the ability of soluble recombinant EGF-like domain to disrupt NRG puncta and by the failure of chimeric TGF_NRG3 (unable to bind ErbB4) to cluster on axonal varicosities that intersect with ErbB4-positive dendrites, remains to be determined. Additional processing of CRD-NRG1 upstream of the EGF-like domain by BACE or ADAM10/17, as reported recently (Fleck et al., 2013), is compatible with this model and would be expected to release the EGF-like domain from either the cell body or the axonal compartment, depending on the subcellular locus of this additional cleavage event. Importantly, while our results indicate that, at low to moderate expression levels, processed dual-pass NRGs preferentially accumulate on axons by virtue of their juxtacrine interactions with ErbB receptors (ErbB4 in neurons and ErbB3 on myelinat- ing glia), their subcellular distribution is likely more widespread in neurons that express higher levels, such as sensory neurons (Canetta et al., 2011). Notwithstanding, a central theme emerging from this work is the notion of isoform-specific short- and long-range signaling by NRGs (Fig. 12A), a concept that is consistent with data from loss-of-function and gain-of-function studies demonstrating that Ig- and Type III NRG1 isoforms are not functionally redundant (Hippenmeyer et al., 2002; Michailov et al., 2004). Our finding showing the requirement of BACE for CRD-NRG1 processing and subsequent interactions with ErbB receptors is also consistent with previous reports of severe hypomyelination in the PNS of BACE-1 KO mice, which essentially phenocopy NRG1 Type III mutant mice (Wolpowitz et al., 2000; Hu et al., 2006; Willem et al., 2006).

\section{NRG3 and CRD-NRG1 share many cell biological properties}

This is the first report to demonstrate that NRG3 is a dual-pass transmembrane protein. It also shows that NRG3 traffics as a processed protein to axons where it interacts with ErbB receptors in juxtacrine manner. NRG3 is therefore in a group with CRDNRG1, both in terms of signaling mode and axonal accumulation, suggesting some functional redundancy. Available data on CRD-NRG1 functions in the CNS point to a role for dual-pass NRGs in the regulation of synaptic transmission, for example, through effects on presynaptic nAChRs (Hancock et al., 2008; Zhong et al., 2008), rather than myelination (Brinkmann et al., 2008). However, ISH analyses in the adult mouse brain indicate that NRG3 expression is higher than CRD-NRG1 in the hippocampus and the neocortex (Longart et al., 2004), where NRG3positive cells likely correspond to glutamatergic associative, commissural, and cortifugal neurons that project to cortical and subcortical structures (Molyneaux et al., 2007). Based on our findings, future studies should focus on the role of NRG3-ErbB4 signaling in the modulation of synaptic properties at postsynaptic targets in projection areas of cortical NRG3-expressing neurons. This is particularly important given the growing body of literature genetically linking NRG3 in mice and humans with cognition and behavioral traits, such as impulsivity and nicotine dependence, that are relevant to many psychiatric disorders (see, e.g., Hayes et al., 2016; Kao et al., 2010; Loos et al., 2014; Tost et al., 2014; Turner et al., 2014).

In conclusion, this work establishes a new conceptual framework to understand NRG isoform diversity in cell biological terms based on findings in cultured hippocampal neurons. It will be interesting to explore whether, and to what extent, the functional relationship between NRG transmembrane topology and subcellular distribution is observed during development and in different central and peripheral neuron types, and to determine whether other alternatively spliced NRG domains not directly tested here, such as the stalk and carboxyl-terminal tail regions, play any role in differential targeting.

\section{References}

Bao J, Wolpowitz D, Role LW, Talmage DA (2003) Back signaling by the Nrg-1 intracellular domain. J Cell Biol 161:1133-1141. CrossRef Medline Bao J, Lin H, Ouyang Y, Lei D, Osman A, Kim TW, Mei L, Dai P, Ohlemiller KK, Ambron RT (2004) Activity-dependent transcription regulation of PSD-95 by neuregulin-1 and Eos. Nat Neurosci 7:1250-1258. CrossRef Medline

Ben Halima S, Mishra S, Raja KM, Willem M, Baici A, Simons K, Brüstle O, Koch P, Haass C, Caflisch A, Rajendran L (2016) Specific inhibition of beta-secretase processing of the Alzheimer disease amyloid precursor protein. Cell Rep 14:2127-2141. CrossRef Medline

Berridge MJ (1998) Neuronal calcium signaling. Neuron 21:13-26. CrossRef Medline 
Birchmeier C, Nave KA (2008) Neuregulin-1, a key axonal signal that drives Schwann cell growth and differentiation. Glia 56:1491-1497. CrossRef Medline

Brewer GJ, Torricelli JR, Evege EK, Price PJ (1993) Optimized survival of hippocampal neurons in B27-supplemented Neurobasal, a new serumfree medium combination. J Neurosci Res 35:567-576. CrossRef Medline

Brinkmann BG, Agarwal A, Sereda MW, Garratt AN, Müller T, Wende H, Stassart RM, Nawaz S, Humml C, Velanac V, Radyushkin K, Goebbels S, Fischer TM, Franklin RJ, Lai C, Ehrenreich H, Birchmeier C, Schwab MH, Nave KA (2008) Neuregulin-1/ErbB signaling serves distinct functions in myelination of the peripheral and central nervous system. Neuron 59:581-595. CrossRef Medline

Buonanno A (2010) The neuregulin signaling pathway and schizophrenia: from genes to synapses and neural circuits. Brain Res Bull 83:122-131. CrossRef Medline

Buonanno A, Fischbach GD (2001) Neuregulin and ErbB receptor signaling pathways in the nervous system. Curr Opin Neurobiol 11:287-296. CrossRef Medline

Canetta SE, Luca E, Pertot E, Role LW, Talmage DA (2011) Type III Nrg1 back signaling enhances functional TRPV1 along sensory axons contributing to basal and inflammatory thermal pain sensation. PLoS One 6:e25108. CrossRef Medline

Carroll SL, Miller ML, Frohnert PW, Kim SS, Corbett JA (1997) Expression of neuregulins and their putative receptors, ErbB2 and ErbB3, is induced during Wallerian degeneration. J Neurosci 17:1642-1659. Medline

Chen YJ, Zhang M, Yin DM, Wen L, Ting A, Wang P, Lu YS, Zhu XH, Li SJ, Wu CY, Wang XM, Lai C, Xiong WC, Mei L, Gao TM (2010) ErbB4 in parvalbumin-positive interneurons is critical for neuregulin 1 regulation of long-term potentiation. Proc Natl Acad Sci U S A 107:21818-21823. CrossRef Medline

Chu GC, Moscoso LM, Sliwkowski MX, Merlie JP (1995) Regulation of the acetylcholine receptor epsilon subunit gene by recombinant ARIA: an in vitro model for transsynaptic gene regulation. Neuron 14:329-339. CrossRef Medline

Corfas G, Rosen KM, Aratake H, Krauss R, Fischbach GD (1995) Differential expression of ARIA isoforms in the rat brain. Neuron 14:103-115. CrossRef Medline

Deardorff AS, Romer SH, Sonner PM, Fyffe RE (2014) Swimming against the tide: investigations of the C-bouton synapse. Front Neural Circuits 8:106. CrossRef Medline

Demaurex N, Furuya W, D’Souza S, Bonifacino JS, Grinstein S (1998) Mechanism of acidification of the trans-Golgi network (TGN): in situ measurements of $\mathrm{pH}$ using retrieval of TGN38 and furin from the cell surface. J Biol Chem 273:2044-2051. CrossRef Medline

Du J, Tao-Cheng JH, Zerfas P, McBain CJ (1998) The $\mathrm{K}^{+}$channel, Kv2.1, is apposed to astrocytic processes and is associated with inhibitory postsynaptic membranes in hippocampal and cortical principal neurons and inhibitory interneurons. Neuroscience 84:37-48. CrossRef Medline

Elenius K, Corfas G, Paul S, Choi CJ, Rio C, Plowman GD, Klagsbrun M (1997) A novel juxtamembrane domain isoform of HER4/ErbB4: isoform-specific tissue distribution and differential processing in response to phorbol ester. J Biol Chem 272:26761-26768. CrossRef Medline

Esper RM, Loeb JA (2004) Rapid axoglial signaling mediated by neuregulin and neurotrophic factors. J Neurosci 24:6218-6227. CrossRef Medline

Falls DL (2003) Neuregulins: functions, forms, and signaling strategies. Exp Cell Res 284:14-30. CrossRef Medline

Fleck D, Garratt AN, Haass C, Willem M (2012) BACE1 dependent neuregulin processing: review. Curr Alzheimer Res 9:178-183. CrossRef Medline

Fleck D, van Bebber F, Colombo A, Galante C, Schwenk BM, Rabe L, Hampel H, Novak B, Kremmer E, Tahirovic S, Edbauer D, Lichtenthaler SF, Schmid B, Willem M, Haass C (2013) Dual cleavage of neuregulin 1 Type III by BACE1 and ADAM17 liberates its EGF-like domain and allows paracrine signaling. J Neurosci 33:7856-7869. CrossRef Medline

Fox PD, Haberkorn CJ, Akin EJ, Seel PJ, Krapf D, Tamkun MM (2015) Induction of stable endoplasmic reticulum/plasma membrane junctions by Kv2.1 potassium channels. J Cell Sci 128:2096-2105. CrossRef Medline

Fukumoto H, Cheung BS, Hyman BT, Irizarry MC (2002) Beta-secretase protein and activity are increased in the neocortex in Alzheimer disease. Arch Neurol 59:1381-1389. CrossRef Medline

Gallart-Palau X, Tarabal O, Casanovas A, Sábado J, Correa FJ, Hereu M, Piedrafita L, Calderó J, Esquerda JE (2014) Neuregulin-1 is concentrated in the postsynaptic subsurface cistern of C-bouton inputs to alpha- motoneurons and altered during motoneuron diseases. FASEB J 28: 3618-3632. CrossRef Medline

Garcia RA, Vasudevan K, Buonanno A (2000) The neuregulin receptor ErbB-4 interacts with PDZ-containing proteins at neuronal synapses. Proc Natl Acad Sci U S A 97:3596-3601. CrossRef Medline

Garratt AN, Britsch S, Birchmeier C (2000) Neuregulin, a factor with many functions in the life of a Schwann cell. Bioessays 22:987-996. CrossRef Medline

Gerecke KM, Wyss JM, Karavanova I, Buonanno A, Carroll SL (2001) ErbB transmembrane tyrosine kinase receptors are differentially expressed throughout the adult rat central nervous system. J Comp Neurol 433:86100. CrossRef Medline

Gu Y, Tran T, Murase S, Borrell A, Kirkwood A, Quinlan EM (2016) Neuregulin-dependent regulation of fast-spiking interneuron excitability controls the timing of the critical period. J Neurosci 36:10285-10295. CrossRef Medline

Hancock ML, Canetta SE, Role LW, Talmage DA (2008) Presynaptic Type III neuregulin1-ErbB signaling targets $\alpha 7$ nicotinic acetylcholine receptors to axons. J Cell Biol 181:511-521. CrossRef Medline

Hayes LN, Shevelkin A, Zeledon M, Steel G, Chen PL, Obie C, Pulver A, Avramopoulos D, Valle D, Sawa A, Pletnikov MV (2016) Neuregulin 3 knockout mice exhibit behaviors consistent with psychotic disorders. Mol Neuropsychiatry 2:79-87. CrossRef Medline

Hayworth CR, Moody SE, Chodosh LA, Krieg P, Rimer M, Thompson WJ (2006) Induction of neuregulin signaling in mouse Schwann cells in vivo mimics responses to denervation. J Neurosci 26:6873-6884. CrossRef Medline

Hippenmeyer S, Shneider NA, Birchmeier C, Burden SJ, Jessell TM, Arber S (2002) A role for neuregulin1 signaling in muscle spindle differentiation. Neuron 36:1035-1049. CrossRef Medline

Ho WH, Armanini MP, Nuijens A, Phillips HS, Osheroff PL (1995) Sensory and motor neuron-derived factor: a novel heregulin variant highly expressed in sensory and motor neurons. J Biol Chem 270:14523-14532. CrossRef Medline

Horiuchi K, Zhou HM, Kelly K, Manova K, Blobel CP (2005) Evaluation of the contributions of ADAMs 9, 12, 15, 17, and 19 to heart development and ectodomain shedding of neuregulins beta1 and beta2. Dev Biol 283: 459-471. CrossRef Medline

Huang YZ, Won S, Ali DW, Wang Q, Tanowitz M, Du QS, Pelkey KA, Yang DJ, Xiong WC, Salter MW, Mei L (2000) Regulation of neuregulin signaling by PSD-95 interacting with ErbB4 at CNS synapses. Neuron 26: 443-455. CrossRef Medline

Hu X, Hicks CW, He W, Wong P, Macklin WB, Trapp BD, Yan R (2006) Bacel modulates myelination in the central and peripheral nervous system. Nat Neurosci 9:1520-1525. CrossRef Medline

Janssen MJ, Leiva-Salcedo E, Buonanno A (2012) Neuregulin directly decreases voltage-gated sodium current in hippocampal ErbB4-expressing interneurons. J Neurosci 32:13889-13895. CrossRef Medline

Jo SA, Zhu X, Marchionni MA, Burden SJ (1995) Neuregulins are concentrated at nerve-muscle synapses and activate ACh-receptor gene expression. Nature 373:158-161. CrossRef Medline

Jones JT, Akita RW, Sliwkowski MX (1999) Binding specificities and affinities of egf domains for ErbB receptors. FEBS Lett 447:227-231. CrossRef Medline

Kang JS, Tian JH, Pan PY, Zald P, Li C, Deng C, Sheng ZH (2008) Docking of axonal mitochondria by syntaphilin controls their mobility and affects short-term facilitation. Cell 132:137-148. CrossRef Medline

Kao WT, Wang Y, Kleinman JE, Lipska BK, Hyde TM, Weinberger DR, Law AJ (2010) Common genetic variation in Neuregulin 3 (NRG3) influences risk for schizophrenia and impacts NRG3 expression in human brain. Proc Natl Acad Sci U S A 107:15619-15624. CrossRef Medline

Kaplan ES, Cooke SF, Komorowski RW, Chubykin AA, Thomazeau A, Khibnik LA, Gavornik JP, Bear MF (2016) Contrasting roles for parvalbuminexpressing inhibitory neurons in two forms of adult visual cortical plasticity. Elife 5:e11450. CrossRef Medline

Kramer R, Bucay N, Kane DJ, Martin LE, Tarpley JE, Theill LE (1996) Neuregulins with an Ig-like domain are essential for mouse myocardial and neuronal development. Proc Natl Acad Sci U S A 93:4833-4838. CrossRef Medline

Krogh A, Larsson B, von Heijne G, Sonnhammer EL (2001) Predicting transmembrane protein topology with a hidden Markov model: application to complete genomes. J Mol Biol 305:567-580. CrossRef Medline

La Marca R, Cerri F, Horiuchi K, Bachi A, Feltri ML, Wrabetz L, Blobel CP, Quattrini A, Salzer JL, Taveggia C (2011) TACE (ADAM17) inhibits Schwann cell myelination. Nat Neurosci 14:857-865. CrossRef Medline 
Liu X, Bates R, Yin DM, Shen C, Wang F, Su N, Kirov SA, Luo Y, Wang JZ, Xiong WC, Mei L (2011) Specific regulation of NRG1 isoform expression by neuronal activity. J Neurosci 31:8491-8501. CrossRef Medline

Loeb JA, Fischbach GD (1995) ARIA can be released from extracellular matrix through cleavage of a heparin-binding domain. J Cell Biol 130:127135. CrossRef Medline

Loeb JA, Susanto ET, Fischbach GD (1998) The neuregulin precursor proARIA is processed to ARIA after expression on the cell surface by a protein kinase C-enhanced mechanism. Mol Cell Neurosci 11:77-91. CrossRef Medline

Longart M, Liu Y, Karavanova I, Buonanno A (2004) Neuregulin-2 is developmentally regulated and targeted to dendrites of central neurons. J Comp Neurol 472:156-172. CrossRef Medline

Loos M, Mueller T, Gouwenberg Y, Wijnands R, van der Loo RJ, Birchmeier C, Smit AB, Spijker S (2014) Neuregulin-3 in the mouse medial prefrontal cortex regulates impulsive action. Biol Psychiatry 76:648-655. CrossRef Medline

Ma Z, Wang J, Song F, Loeb JA (2011) Critical period of axoglial signaling between neuregulin-1 and brain-derived neurotrophic factor required for early Schwann cell survival and differentiation. J Neurosci 31:9630-9640. CrossRef Medline

Mei L, Nave KA (2014) Neuregulin-ERBB signaling in the nervous system and neuropsychiatric diseases. Neuron 83:27-49. CrossRef Medline

Meyer D, Birchmeier C (1994) Distinct isoforms of neuregulin are expressed in mesenchymal and neuronal cells during mouse development. Proc Natl Acad Sci U S A 91:1064-1068. CrossRef Medline

Meyer D, Yamaai T, Garratt A, Riethmacher-Sonnenberg E, Kane D, Theill LE, Birchmeier C (1997) Isoform-specific expression and function of neuregulin. Development 124:3575-3586. Medline

Michailov GV, Sereda MW, Brinkmann BG, Fischer TM, Haug B, Birchmeier C, Role L, Lai C, Schwab MH, Nave KA (2004) Axonal neuregulin-1 regulates myelin sheath thickness. Science 304:700-703. CrossRef Medline

Misonou H, Mohapatra DP, Park EW, Leung V, Zhen D, Misonou K, Anderson AE, Trimmer JS (2004) Regulation of ion channel localization and phosphorylation by neuronal activity. Nat Neurosci 7:711-718. CrossRef Medline

Molyneaux BJ, Arlotta P, Menezes JR, Macklis JD (2007) Neuronal subtype specification in the cerebral cortex. Nat Rev Neurosci 8:427-437. CrossRef Medline

Montero JC, Yuste L, Díaz-Rodríguez E, Esparís-Ogando A, Pandiella A (2000) Differential shedding of transmembrane neuregulin isoforms by the tumor necrosis factor-alpha-converting enzyme. Mol Cell Neurosci 16:631-648. CrossRef Medline

Morishita H, Cabungcal JH, Chen Y, Do KQ, Hensch TK (2015) Prolonged period of cortical plasticity upon redox dysregulation in fast-spiking interneurons. Biol Psychiatry 78:396-402. CrossRef Medline

Moscoso LM, Chu GC, Gautam M, Noakes PG, Merlie JP, Sanes JR (1995) Synapse-associated expression of an acetylcholine receptor-inducing protein, ARIA/heregulin, and its putative receptors, ErbB2 and ErbB3, in developing mammalian muscle. Dev Biol 172:158-169. CrossRef Medline

Mulholland PJ, Carpenter-Hyland EP, Hearing MC, Becker HC, Woodward JJ, Chandler LJ (2008) Glutamate transporters regulate extrasynaptic NMDA receptor modulation of Kv2.1 potassium channels. J Neurosci 28:8801-8809. CrossRef Medline

Murakoshi H, Shi G, Scannevin RH, Trimmer JS (1997) Phosphorylation of the $\mathrm{Kv} 2.1 \mathrm{~K}^{+}$channel alters voltage-dependent activation. Mol Pharmacol 52:821-828. CrossRef Medline

Nagano O, Murakami D, Hartmann D, De Strooper B, Saftig P, Iwatsubo T, Nakajima M, Shinohara M, Saya H (2004) Cell-matrix interaction via CD44 is independently regulated by different metalloproteinases activated in response to extracellular $\mathrm{Ca}(2+)$ influx and PKC activation. J Cell Biol 165:893-902. CrossRef Medline

Nave KA, Salzer JL (2006) Axonal regulation of myelination by neuregulin 1. Curr Opin Neurobiol 16:492-500. CrossRef Medline

Peirson SN, Butler JN, Foster RG (2003) Experimental validation of novel and conventional approaches to quantitative real-time PCR data analysis. Nucleic Acids Res 31:e73. CrossRef Medline

Pizzorusso T, Medini P, Berardi N, Chierzi S, Fawcett JW, Maffei L (2002) Reactivation of ocular dominance plasticity in the adult visual cortex. Science 298:1248-1251. CrossRef Medline
Shamir A, Kwon OB, Karavanova I, Vullhorst D, Leiva-Salcedo E, Janssen MJ, Buonanno A (2012) The importance of the NRG-1/ErbB4 pathway for synaptic plasticity and behaviors associated with psychiatric disorders. J Neurosci 32:2988-2997. CrossRef Medline

Stassart RM, Fledrich R, Velanac V, Brinkmann BG, Schwab MH, Meijer D, Sereda MW, Nave KA (2013) A role for Schwann cell-derived neuregulin-1 in remyelination. Nat Neurosci 16:48-54. CrossRef Medline

Steinthorsdottir V, Stefansson H, Ghosh S, Birgisdottir B, Bjornsdottir S, Fasquel AC, Olafsson O, Stefansson K, Gulcher JR (2004) Multiple novel transcription initiation sites for NRG1. Gene 342:97-105. CrossRef Medline

Sun Y, Ikrar T, Davis MF, Gong N, Zheng X, Luo ZD, Lai C, Mei L, Holmes TC, Gandhi SP, Xu X (2016) Neuregulin-1/ErbB4 signaling regulates visual cortical plasticity. Neuron 92:160-173. CrossRef Medline

Tan W, Wang Y, Gold B, Chen J, Dean M, Harrison PJ, Weinberger DR, Law AJ (2007) Molecular cloning of a brain-specific, developmentally regulated neuregulin 1 (NRG1) isoform and identification of a functional promoter variant associated with schizophrenia. J Biol Chem 282:2434324351. CrossRef Medline

Tost H, Callicott JH, Rasetti R, Vakkalanka R, Mattay VS, Weinberger DR, Law AJ (2014) Effects of neuregulin 3 genotype on human prefrontal cortex physiology. J Neurosci 34:1051-1056. CrossRef Medline

Turner JR, Ray R, Lee B, Everett L, Xiang J, Jepson C, Kaestner KH, Lerman C, Blendy JA (2014) Evidence from mouse and man for a role of neuregulin 3 in nicotine dependence. Mol Psychiatry 19:801-810. CrossRef Medline

Vassar R, Bennett BD, Babu-Khan S, Kahn S, Mendiaz EA, Denis P, Teplow DB, Ross S, Amarante P, Loeloff R, Luo Y, Fisher S, Fuller J, Edenson S, Lile J, Jarosinski MA, Biere AL, Curran E, Burgess T, Louis JC, et al. (1999) Betasecretase cleavage of Alzheimer's amyloid precursor protein by the transmembrane aspartic protease BACE. Science 286:735-741. CrossRef Medline

Vullhorst D, Neddens J, Karavanova I, Tricoire L, Petralia RS, McBain CJ, Buonanno A (2009) Selective expression of ErbB4 in interneurons, but not pyramidal cells, of the rodent hippocampus. J Neurosci 29:1225512264. CrossRef Medline

Vullhorst D, Mitchell RM, Keating C, Roychowdhury S, Karavanova I, TaoCheng JH, Buonanno A (2015) A negative feedback loop controls NMDA receptor function in cortical interneurons via neuregulin 2/ErbB4 signalling. Nat Commun 6:7222. CrossRef Medline

Wang F, Flanagan J, Su N, Wang LC, Bui S, Nielson A, Wu X, Vo HT, Ma XJ, Luo Y (2012) RNAscope: a novel in situ RNA analysis platform for formalin-fixed, paraffin-embedded tissues. J Mol Diagn 14:22-29. CrossRef Medline

Wang JY, Miller SJ, Falls DL (2001) The N-terminal region of neuregulin isoforms determines the accumulation of cell surface and released neuregulin ectodomain. J Biol Chem 276:2841-2851. CrossRef Medline

Watanabe N, Mitchison TJ (2002) Single-molecule speckle analysis of actin filament turnover in lamellipodia. Science 295:1083-1086. CrossRef Medline

Willem M, Garratt AN, Novak B, Citron M, Kaufmann S, Rittger A, DeStrooper B, Saftig P, Birchmeier C, Haass C (2006) Control of peripheral nerve myelination by the beta-secretase BACE1. Science 314: 664-666. CrossRef Medline

Wolpowitz D, Mason TB, Dietrich P, Mendelsohn M, Talmage DA, Role LW (2000) Cysteine-rich domain isoforms of the neuregulin-1 gene are required for maintenance of peripheral synapses. Neuron 25:79-91. CrossRef Medline

Yamashiro DJ, Maxfield FR (1984) Acidification of endocytic compartments and the intracellular pathways of ligands and receptors. J Cell Biochem 26:231-246. CrossRef Medline

Yan R, Han P, Miao H, Greengard P, Xu H (2001) The transmembrane domain of the Alzheimer's beta-secretase (BACE1) determines its late Golgi localization and access to beta-amyloid precursor protein (APP) substrate. J Biol Chem 276:36788-36796. CrossRef Medline

Zhang D, Sliwkowski MX, Mark M, Frantz G, Akita R, Sun Y, Hillan K, Crowley C, Brush J, Godowski PJ (1997) Neuregulin-3 (NRG3): a novel neural tissue-enriched protein that binds and activates ErbB4. Proc Natl Acad Sci U S A 94:9562-9567. CrossRef Medline

Zhong C, Du C, Hancock M, Mertz M, Talmage DA, Role LW (2008) Presynaptic Type III neuregulin 1 is required for sustained enhancement of hippocampal transmission by nicotine and for axonal targeting of alpha7 nicotinic acetylcholine receptors. J Neurosci 28:9111-9116. CrossRef Medline 